\title{
On the Utility of Coated POSS-Polyimides for Vehicles in Very Low Earth Orbit (VLEO)
}

Timothy K. Minton ${ }^{1,2, *} \cdot$ Thomas E. Schwartzentruber ${ }^{2} \cdot$ Chenbiao Xu $^{1}$

\section{Abstract}

The environment encountered by space vehicles in very low Earth orbit (VLEO, $180-350 \mathrm{~km}$ altitude) contains predominantly atomic oxygen $(\mathrm{AO})$ and molecular nitrogen $\left(\mathrm{N}_{2}\right)$, which collide with ram surfaces at relative velocities of $\sim 7.5 \mathrm{~km} \mathrm{~s}^{-1}$. Structural, thermal-control, and coating materials containing organic polymers are particularly susceptible to AO attack at these high velocities, resulting in erosion, roughening, and degradation of function. Copolymerization or blending of a polymer with polyhedral oligomeric silsesquioxane (POSS) yields a material that can resist AO attack through the formation of a passivating silicon-oxide layer. Still, these hybrid organic/inorganic polymers become rough through AO reactions as the passivating layer is forming. Surface roughness may enhance satellite drag because it promotes energy transfer and scattering angle randomization during gas-surface collisions. As potential low-drag and AOresistant materials, we have investigated POSS-containing films of clear and Kapton-like polyimides that have an atomically smooth AO-resistant coating of $\mathrm{Al}_{2} \mathrm{O}_{3}$ that is grown by atomic layer deposition (ALD). Coated and uncoated films were exposed to hyperthermal molecular beams containing atomic and molecular oxygen to investigate their AO resistance, and molecular beam-surface scattering studies were conducted to characterize the gas-surface scattering dynamics on pristine and AO-exposed surfaces to inform drag predictions. The $\mathrm{AO}$ erosion yield of $\mathrm{Al}_{2} \mathrm{O}_{3} \mathrm{ALD}$-coated films is essentially zero. Simulations of drag on a representative satellite structure that are based on the observed scattering dynamics suggest that the use of the $\mathrm{Al}_{2} \mathrm{O}_{3}$ ALD-coated POSS-polyimides on external satellite surfaces have the potential to

\footnotetext{
${ }^{1}$ Smead Department of Aerospace Engineering Sciences, University of Colorado, Boulder, CO 80303 USA

${ }^{2}$ Skeyeon, Inc., 440 San Antonio Ave., Suite 12, San Diego, CA 92106 USA

* Corresponding author: tminton@colorado.edu
} 
reduce drag to less than half that predicted for diffuse scattering surfaces. These smooth and AO-resistant polymer films thus show promise for use in the extreme oxidizing and high-drag environment in VLEO.

Keywords Atomic oxygen $\cdot$ POSS polyimide $\cdot$ Erosion yield $\cdot$ Low drag $\cdot$ Very low Earth orbit

\section{Introduction}

There is significant interest in the commercial use of very low Earth orbit (VLEO, $180-350 \mathrm{~km}$ in altitude), as a result of an unmet need for high revisit rate (less than hourly) Earth observation that can generate high resolution $(\sim 1 \mathrm{~m})$ images. ${ }^{1-4}$ However, VLEO altitudes have long been avoided because of the high density and harsh oxidizing environment of the residual atmosphere. VLEO environments contain predominantly atomic oxygen $(\mathrm{AO})$ and molecular nitrogen $\left(\mathrm{N}_{2}\right)$, which collide with ram surfaces on spacecraft at relative velocities of $\sim 7.5 \mathrm{~km} \mathrm{~s}^{-1} .^{5-11}$ Structural, thermal-control, and coating materials containing organic polymers are particularly susceptible to $\mathrm{AO}$ attack at these high velocities, resulting in erosion, roughening, and degradation of function. ${ }^{12-27}$ Furthermore, the high densities of the atmosphere at VLEO altitudes, on the order of $10^{9} \mathrm{~cm}^{-3},{ }^{5-7}$ cause sufficient drag to require a propulsion system for a satellite to maintain orbit, leading to increased mass and complexity. To maximize the survivability of a VLEO satellite while minimizing cost, the satellite must be designed to have low drag and high AO resistance. Thus, an appropriately-designed VLEO satellite would be expected to have materials on its exterior surfaces that are highly AO-resistant while keeping gas-surface energy and momentum transfer to a minimum. Polymers are desired over inorganic materials because of their significant weight advantage and the ease with which their functions can be tailored using different chemical formulations.

A general approach to producing AO-resistant polymeric materials is copolymerization or blending of an organic polymer with polyhedral oligomeric silsesquioxane (POSS) to yield a hybrid organic/inorganic nanocomposite material that can resist $\mathrm{AO}$ attack through the formation of a passivating $\mathrm{SiO}_{\mathrm{x}}$ layer, while not significantly altering the mechanical or optical properties of the base organic 


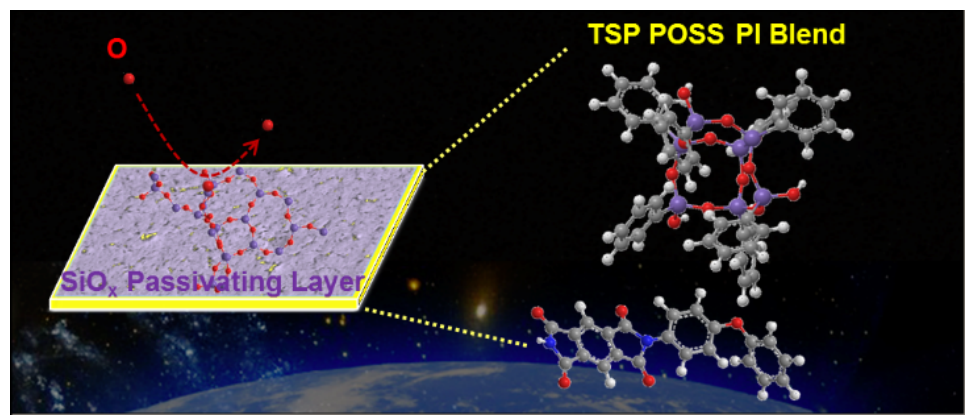

Figure 1. A blend of TSP POSS with PMDA-ODA polyimide, with a $\sim 7$ wt\% $\mathrm{Si}_{7} \mathrm{O}_{9}$ POSS cage, forms a passivating $\mathrm{SiO}_{x}$ layer when bombarded by atomic oxygen. As the passivating oxide forms, the surface becomes rough.

polymer. ${ }^{28-32}$ This approach to produce light-weight and flexible AO-resistant materials has been investigated for nearly two decades, primarily with POSS variants of the Kapton-like polyimide, poly(pyromellitic dianhydride-co-4,4'-oxydianiline), often referred to as PMDA-ODA, and more recently with a fluorine-containing polyimide, $\mathrm{CORIN}^{\circledR}$, based on the NASA-developed CP1, ${ }^{33}$ which is clear and soluble, making it processable at room temperature. ${ }^{32}$ Figure 1 illustrates the concept with trisilanolphenyl (TSP) POSS blended with a PMDA-ODA polyimide. It has been shown that the AO resistance of POSScontaining PMDA-ODA materials is essentially determined by the weight percentage of the $\mathrm{POSS} \mathrm{Si}_{\mathrm{x}} \mathrm{O}_{\mathrm{y}}$ cage in the material and not how the POSS is incorporated into the polymer. ${ }^{31}$ This result points to the potential of POSS blends as the most low-cost approach to producing AO-resistant POSS-based nanocomposites. However, a more recent study suggested that the relationship between POSS cage content and $\mathrm{AO}$ resistance might not be so simple when relating the $\mathrm{AO}$ resistance to POSS content of different polyimide types. ${ }^{32}$ Nevertheless, the general approach of preparing POSS-containing, AO-resistant polymers has been demonstrated for two different polyimides that could serve as replacements for Kapton and FEP Teflon, which are ubiquitous satellite materials that would etch significantly in a VLEO environment. ${ }^{31,32}$

As mentioned above, external surfaces of VLEO satellites must be AO-resistant while remaining very smooth. An atomically-smooth surface is needed to reduce scattering angle randomization and energy transfer from incident atoms or molecules, thereby minimizing momentum transfer and therefore drag (see 

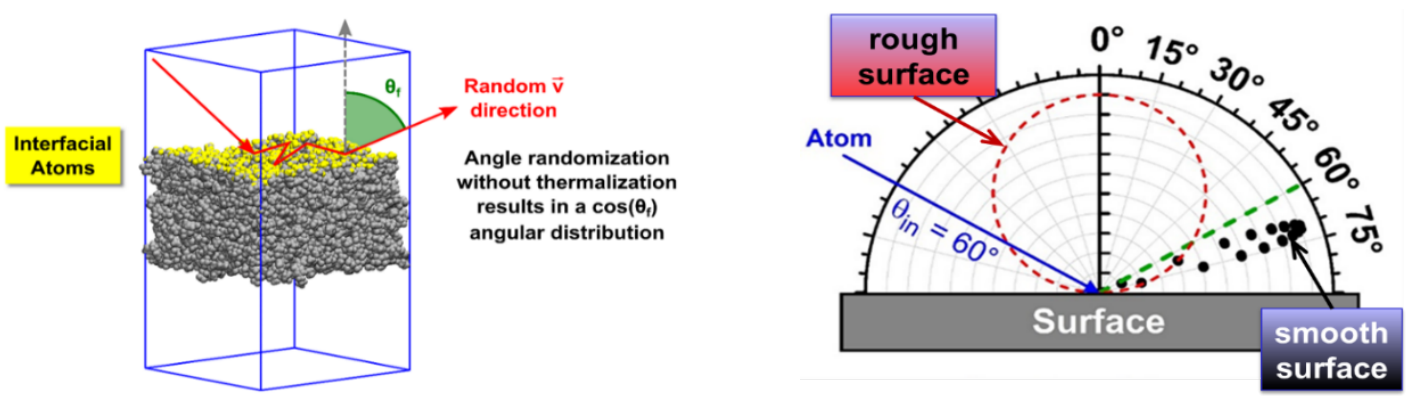

Figure 2. When a stream of atoms or molecules encounters an atomically rough surface, there is typically high energy and momentum accommodation on the surface as a result of multiple bounces, and the scattered products exit the surface in a cosine angular distribution about the surface normal with significant loss of their incident energies. This is referred to as diffuse scattering, and such scattering results in maximum drag. If incident atoms or molecules scatter from a smooth surface in the forward (specular or super-specular) direction while retaining most of their incident kinetic energy, then drag is significantly reduced.

Fig. 2). However, POSS-containing polymers develop rough surfaces even though they are generally AOresistant, ${ }^{30-32}$ so they are not ideal for use in VLEO without additional protection from a coating. Inorganic coatings are usually AO-resistant and they can have smooth surfaces. However, if a polymer substrate reacts significantly with $\mathrm{AO}$, then it will erode near a defect and cause the coating to be undercut and flake off, leading to further erosion and general roughening of the surface (Fig. 3). ${ }^{9,34,35}$ Coating defects are ubiquitous, as they are inherent in conventional vapor deposition, chemical vapor deposition, and plasmaenhanced chemical vapor deposition methods. Furthermore, material handling, thermal cycling, and micrometeoroids and orbital debris can create new defects. Therefore, a coating alone is not sufficient to maintain a smooth surface under the harsh oxidizing conditions of VLEO. Nevertheless, the use of a smooth AO-resistant inorganic coating on a POSS-polyimide substrate can create a material that is essentially impervious to AO attack while remaining extremely smooth. If a defect forms in the coating, the exposed

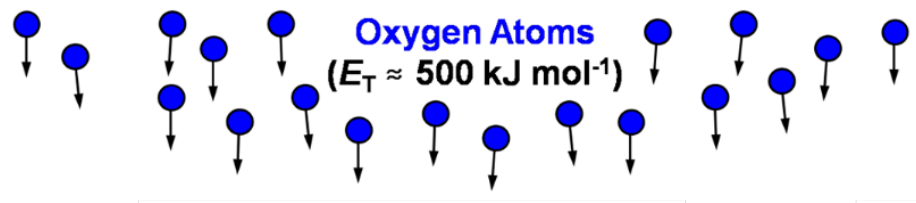

Figure 3. Schematic representations of coated polymers that are under attack by hyperthermal $O$ atoms in VLEO. If the polymer substrate is highly reactive with $O$ atoms, the substrate will etch severely, causing undercutting and spallation of the coating and growth of the defect. A highly AO-resistant substrate will lead to minimal erosion of the substrate near coating defect, preventing undercutting and High O-Atom Reactivity 
POSS-containing substrate will erode minimally and the coating will not be undercut and will therefore not flake off. The defect would introduce a local spot of roughness, but as long as the defect density is low the overall surface will remain smooth and the drag should only be negligibly affected. The surface smoothness in the context of satellite drag is not simply defined by metrics such as rms roughness or the arrangement of atoms at the surface. Even a single-crystal surface may present a corrugated interaction potential to a high-energy incident atom, ${ }^{36-38}$ yet high-incident-energy atoms might also scatter mostly in the specular direction even if an atomic force microscope image suggests that a surface is rough on an atomic scale. ${ }^{19}$, 36-44 The key to assessing the drag potential of a surface is thus to characterize the scattering dynamics of $\mathrm{O}$ and $\mathrm{N}_{2}$ molecules that impinge on the surface with orbital velocities.

The atomic-layer deposition (ALD) technique ${ }^{45}$ can be used to deposit an atomically-smooth, conformal, and pinhole-free coating of various metals, metal oxides, and semiconductor oxides on almost any polymer. ALD coatings are conformal, so they are at least as smooth as the surface of the underlying polymer. In practice, the buildup of many atomic layers on the surface actually tends to smooth over imperfections in the polymer surface on the nanometer scale, making the resulting coating surface even smoother than that of the substrate. A pristine POSS polyimide surface can be prepared routinely with an rms roughness of $\sim 2.5 \mathrm{~nm},,^{28,31,32}$ so one would expect that the surface of an ALD coating on this substrate would be smoother than this. ALD coatings of $\mathrm{Al}_{2} \mathrm{O}_{3}$ have been shown to protect a polymer from $\mathrm{AO}$ attack with a thickness of as little at $30 \AA{ }^{46,47}$ and the fact that $\mathrm{Al}$ and $\mathrm{O}$ contain relatively small ion cores makes an atomically-smooth $\mathrm{Al}_{2} \mathrm{O}_{3}$ surface a good candidate for minimal energy or momentum transfer when a hyperthermal $\mathrm{O}$ atom impinges on the surface. ${ }^{38}$ We have thus chosen to investigate the efficacy of $\mathrm{Al}_{2} \mathrm{O}_{3}$ ALD-coated POSS-polyimide films as a low-drag, AO-resistant materials for potential use in VLEO.

A hyperthermal molecular beam containing oxygen atoms was used both to investigate the effects of AO on various sample surfaces and to study the gas-surface scattering dynamics on coated and uncoated surfaces that had been exposed to AO. A highly polished single-crystal $\mathrm{Al}_{2} \mathrm{O}_{3}$ (i.e., sapphire) surface was used as a reference to represent the ideal case for $\mathrm{O}$ atoms scattering on an $\mathrm{Al}_{2} \mathrm{O}_{3}$ surface. The gas-surface scattering data were used directly within particle simulations capable of accurately predicting the drag for 
a representative satellite geometry. The results show that the $\mathrm{Al}_{2} \mathrm{O}_{3}$ ALD-coated, POSS-polyimide films hold great promise for VLEO applications.

\section{Materials and Methods}

\subsection{Atomic-oxygen exposure}

Studies of the AO effects on samples were conducted with a laser-detonation source that produced a pulsed beam containing hyperthermal $\mathrm{O}$ atoms and $\mathrm{O}_{2}$ molecules traveling at an average velocity of $\sim 8 \mathrm{~km} \mathrm{~s}^{-1}$, as has been described previously. ${ }^{20,28,31,32,46,47}$ A diagram of the experimental setup is shown in Fig. 4a, and the measured translational energy distributions and mole fractions of the atomic and molecular oxygen components of a representative beam are shown in Fig. 4b. Also shown in Fig. $4 \mathrm{~b}$ is the relationship between the O-atom translational energy distribution measured in the experiment and those that have been reported in the literature. ${ }^{11,48}$ The hyperthermal beam is formed by the laser detonation of $\mathrm{O}_{2}$ gas, which is
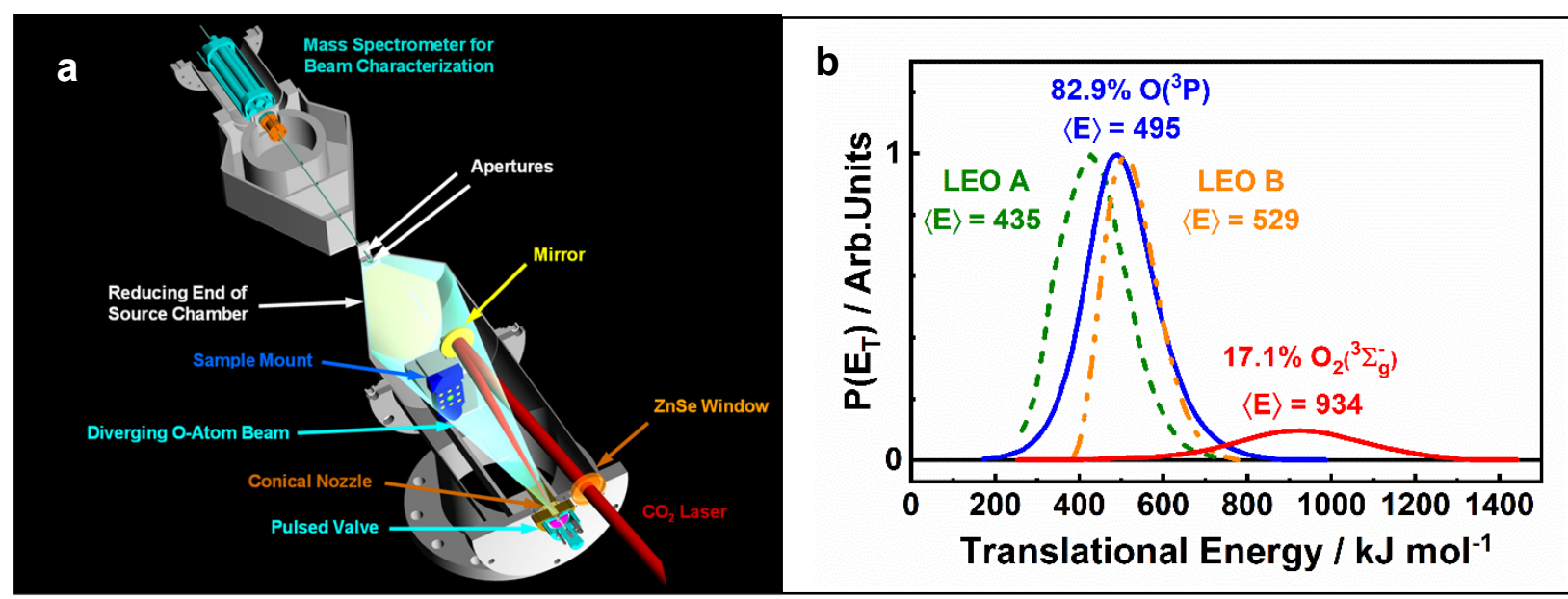

Figure 4. Experimental setup for hyperthermal atomic-oxygen beam exposure with a 9-position sample holder. (b) Translational energy distributions of the $\mathrm{O}$ and $\mathrm{O}_{2}$ components of the beam. The electronic state, average energy (in $\mathrm{kJ} \mathrm{mol}^{-1}$ ), and mole fractions of $\mathrm{O}$ and $\mathrm{O}_{2}$ are shown in blue and red text, respectively. The average energy of the incident $O$ atoms and the width of the incident energy distribution (blue) are similar to what have been reported in the literature ("LEO A"11 and "LEO B"148).

injected, with a stagnation pressure of $550 \mathrm{psi}$, through a $1 \mathrm{~mm}$ orifice into a conical nozzle with the use of a home-built piezoelectric pulsed valve. A $7 \mathrm{~J}$ pulse from a $\mathrm{CO}_{2}$ TEA laser is focused into the throat of the nozzle and heats the resulting plasma to more than $40,000 \mathrm{~K}$, which creates a shock wave that causes the 
$\mathrm{O}_{2}$ molecules to dissociate and/or accelerate out of the nozzle to a nominal velocity of $8 \mathrm{~km} / \mathrm{s}$. The beam is characterized by a quadrupole mass spectrometer aligned with the source, as seen in Fig. 4a. The number density of mass-selected atoms or molecules is measured with the detector as a function of time after the beam pulse is formed. Because species mass and the flight path length from the nozzle to the electronimpact ionizer of the detector are known, the number density distribution as a function of time, $N(t)$, for a given atomic or molecular species may be converted to a probability density distribution as a function of translational energy, $P\left(E_{T}\right)$, which is directly proportional to flux. The mole fractions of $\mathrm{O}$ and $\mathrm{O}_{2}$ in the beam used for the exposures were $82.9 \%$ and $17.1 \%$, respectively. Based on earlier work of Garton et al., ${ }^{49}$, ${ }^{50}$ and Troya et al., ${ }^{51}$ we can conclude that $\mathrm{O}$ and $\mathrm{O}_{2}$ were in their ground ${ }^{3} \mathrm{P}$ and ${ }^{3} \Sigma_{g}^{-}$states, respectively.

Previous work has also allowed us to infer that the ion fraction of the beam is less than $10^{-4}$. Given the species composition and their translational energy distributions, this beam provides a faithful representation of the LEO/VLEO environment in the laboratory. The beam operated at a pulse repetition rate of $2 \mathrm{~Hz}$. For the exposure described here, a sample holder was placed $40 \mathrm{~cm}$ from the apex of the conical nozzle, and the samples in the holder were subjected to 450,000 pulses of the hyperthermal oxygen beam, corresponding to a Kapton-referenced AO fluence of $>1.2 \times 10^{21} \mathrm{O}$ atoms $\mathrm{cm}^{-2}$ (see below).

Six sample types were exposed on the sample holder, and the sample configuration is shown in Fig. 5. 15-inch diameter films of two POSS-containing polyimides were synthesized by Nexolve Holding Company of Huntsville, AL. One polyimide was $\mathrm{CORIN}^{\circledR},{ }^{32}$ which is clear and soluble, and the other polyimide was a POSS-containing variant of Novastrat ${ }^{\circledR} 905$, hereafter referred to simply as Novastrat ${ }^{\circledR}$, which is amber in color and has similar properties as Kapton. ${ }^{52}$ For the present studies, a custom POSSNovastrat ${ }^{\circledR}$ film was prepared by blending trisilanolphenyl (TSP) POSS monomers with the polyamic acid precursor of Novastrat ${ }^{\mathbb{B}}$, with a POSS loading of $7.2 \mathrm{wt} \% \mathrm{Si}_{7} \mathrm{O}_{9}$ cages, and then curing the blend until the polyimide was fully imidized. The synthesized films of CORIN ${ }^{\circledR}$ and POSS-Novastrat ${ }^{\circledR}$ were 45 and 50 $\mu \mathrm{m}$ thick, respectively, and squares of roughly $1 \times 1$ inch were cut from the 15 -inch diameter films that 

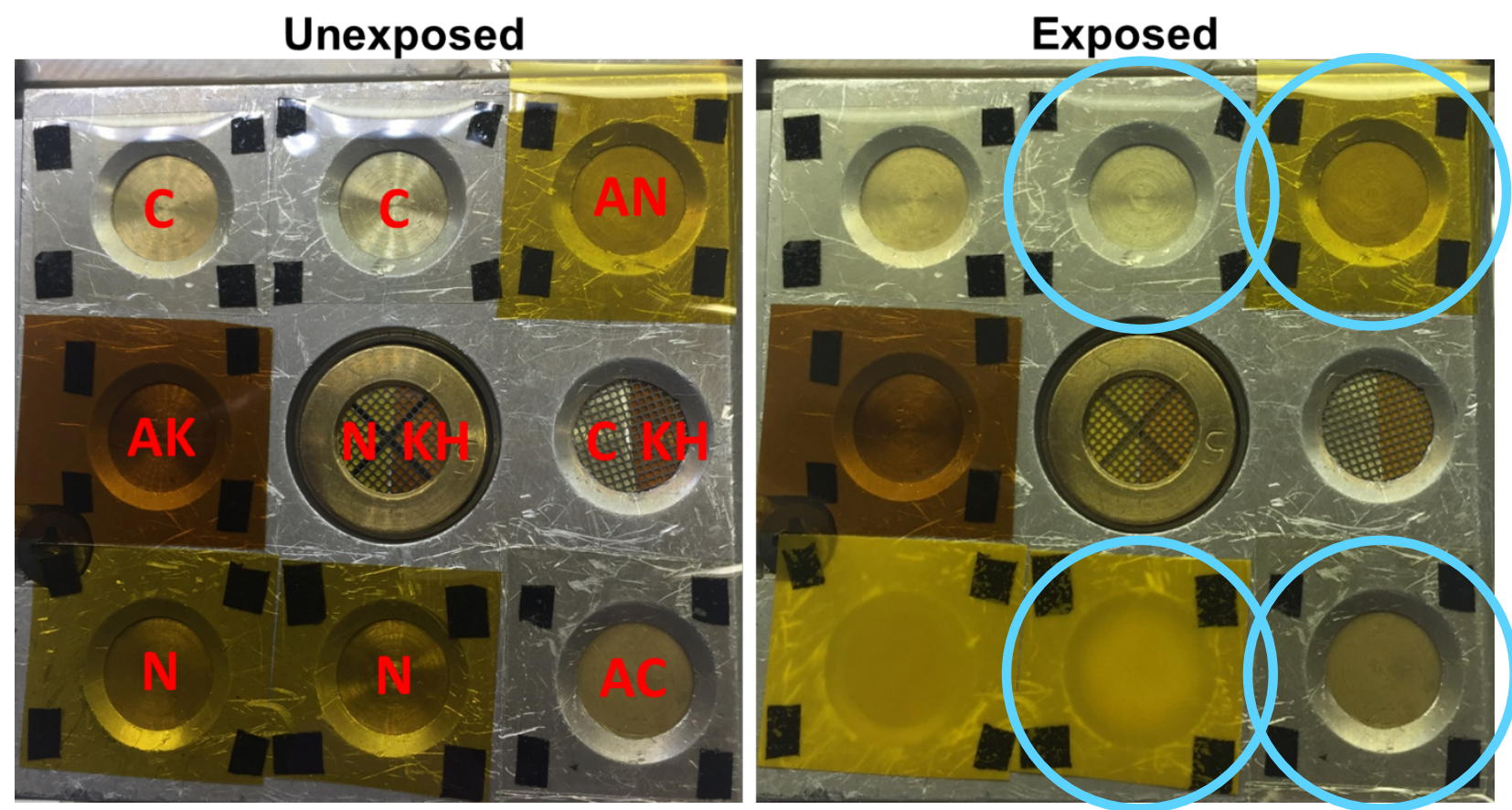

Figure 5. Photographs of the samples mounted to the holder before (left) and after (right) exposure to 450,000 pulses of the hyperthermal $\mathrm{O} / \mathrm{O}_{2}$ beam. Square samples were attached by pieces of double-sided carbon tape, and halfround samples were mounted behind stainless steel etched mesh. The identities of the samples are labeled according to the following key: $C=$ uncoated $C O R I N^{\circledR} ; A C=A I_{2} O_{3}$-coated $C O R I N^{\circledR} ; N=$ uncoated Nexolve Novastrat ${ }^{\circledR} 905$ blended with 7.2 wt\% Si7 $\mathrm{O}_{9}$ TSP POSS; $\mathrm{AN}=\mathrm{Al}_{2} \mathrm{O}_{3}$-coated Nexolve Novastrat ${ }^{\circledR} 905$ blended with 7.2 wt\% $\mathrm{Si}_{7} \mathrm{O}_{9} \mathrm{TSP} P \mathrm{POSS} ; \mathrm{KH}=$ uncoated Kapton $\mathrm{H} ; A K=\mathrm{Al}_{2} \mathrm{O}_{3}$-coated Kapton $\mathrm{H}$. The $\mathrm{C}$ and $\mathrm{N}$ samples appeared cloudy after the exposure as a result of enhanced surface roughness, whereas the $A N, A K$, and $A C$ samples showed essentially no change. The $K H$ samples also became rough, but this is not obvious in the photos. The blue circles on the right photo indicate four of the five samples that were used for the molecular beam-surface scattering experiments.

were synthesized. Samples of Kapton H, $125 \mu \mathrm{m}$ thick, were supplied from old commercial stock, courtesy of Bruce Banks of NASA Glenn Research Center. Some samples received ALD coatings of $\mathrm{Al}_{2} \mathrm{O}_{3}$, which were deposited by ALD NanoSolutions (now Forge Nano) using a standard batch technique, with 100 cycles of trimethylaluminum $/ \mathrm{H}_{2} \mathrm{O},{ }^{46,53,54}$ which produced coatings that were $\sim 100 \AA$ thick.

\subsection{Post-exposure characterization}

For the samples that were covered with stainless steel screens during exposure, a Dektak-3 surface profiler, with a $25 \mu \mathrm{m}$ radius stylus, was used to measure step heights between the exposed and unexposed regions. Thirty step heights were measured for each sample, and the average step height and standard deviation were determined. 
Surface morphology was investigated by scanning electron microscopy with the use of a Zeiss SUPRA 55 VP SEM microscope. Exposed and unexposed samples were prepared by conductively mounting the samples to an aluminum disc with carbon tape and sputtering $15 \mathrm{~nm}$ of gold onto the assembly and placing them into the SEM vacuum chamber. Images were taken at a variety of magnifications between 500x and 10kx.

TappingMode ${ }^{\mathrm{TM}}$ AFM images were collected in ambient conditions on a VEECO MultiMode V/Dimension 3100. The images had dimensions of $10 \times 10 \mu \mathrm{m}$. RMS roughness measurements were made with the instrument's software.

\subsection{Molecular beam-surface scattering dynamics}

Studies of gas-surface scattering dynamics utilized the same apparatus that was used for AO exposures, but reconfigured for beam-surface scattering, as shown in Fig. 6a. This figure illustrates the concept of the beam-surface scattering approach that has been used to understand energy transfer and reactivity at the gassurface interface. ${ }^{36,37}$ A beam of incident atoms or molecules is directed at a surface at a given angle of incidence with respect to the surface normal, and the products that scatter from the surface are detected as a function of their scattering angle (or final angle) and arrival time with the use of a rotatable mass spectrometer detector. This apparatus has been used for many years to study the dynamics of hyperthermal
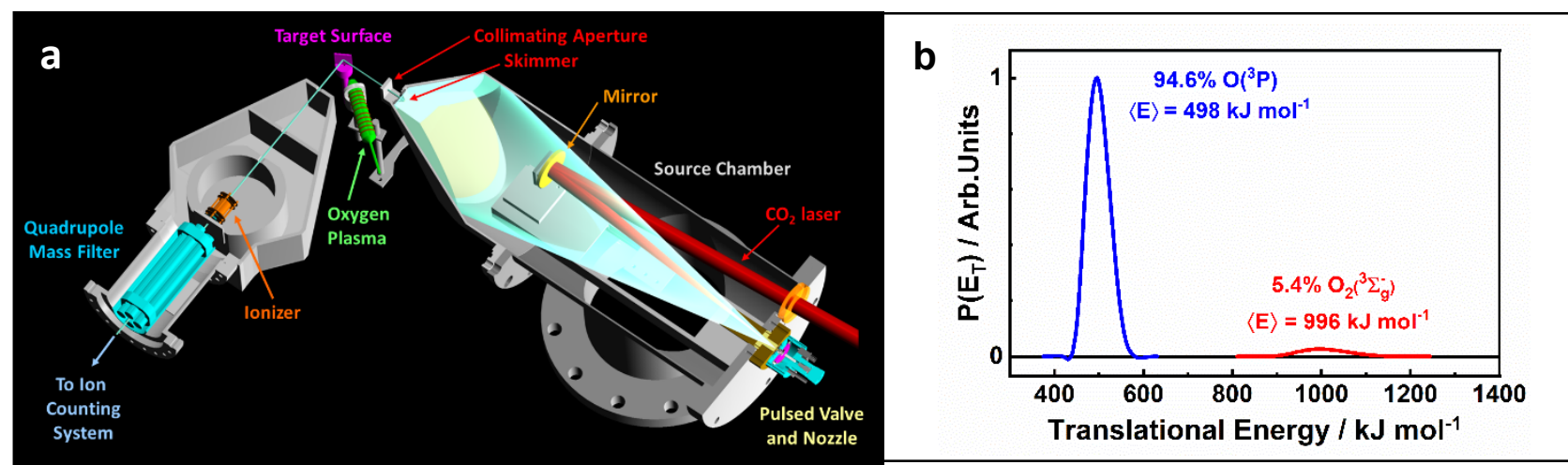

Figure 6. (a) Experimental setup for molecular beam-surface scattering experiments with the hyperthermal atomicoxygen beam. The laser-detonation source, target surface, and rotatable mass spectrometer detector are shown. A velocity-selecting chopper whee ${ }^{59}$ between the collimating aperture and the target surface is not shown. (b) Translational energy distributions, average energies, and electronic states of the $\mathrm{O}$ and $\mathrm{O}_{2}$ components of the beam. 
O-atom collisions with surfaces, ${ }^{17,19,38,42,43,55-59}$ so the technique will be only briefly described here. The hyperthermal beam passed through a skimmer, which was $93 \mathrm{~cm}$ from the nozzle orifice and had a diameter of $2 \mathrm{~mm}$, and was further collimated by a $1.3 \mathrm{~mm}$ diameter aperture that was $3.5 \mathrm{~cm}$ from the skimmer. The total distance between the nozzle orifice and the sample surface (the center of rotation of the mass spectrometer detector) was $99.2 \mathrm{~cm}$, and the distance from the surface to the electron-impact ionizer of the detector was $34.4 \mathrm{~cm}$. Because of the long distance from the nozzle to the $1.3 \mathrm{~mm}$ diameter aperture and the close proximity of the aperture to the sample surface, the diameter of the beam that impinged on the surface was $\sim 1.3 \mathrm{~mm}$. A synchronized chopper wheel, with three centrally-symmetric $1.5 \mathrm{~mm}$ wide slots rotating at $300 \mathrm{~Hz}$, was used to select a narrow velocity distribution from the overall beam pulse before the pulse reached the surface. Fig. $6 \mathrm{~b}$ shows the translational energy distributions of the $\mathrm{O}$ and $\mathrm{O}_{2}$ components of the beam for beam-surface scattering experiments. This velocity-selected beam was directed at a (temperature-controlled) target surface at an angle of incidence, $\theta_{i}=70^{\circ}$, with respect to the surface normal. Such a grazing angle was chosen because it is anticipated that a VLEO vehicle would have a sharp leading edge to allow for minimal energy transfer in the structure scattering regime. ${ }^{36}$

The products that scattered inelastically from the surface were collected with the use of the rotatable mass spectrometer detector. The primary data were number density distributions as a function of flight time, $t$, from the surface to the electron-impact ionizer, at a specific final angle, $\theta_{f}$. These $N(t)$ distributions for mass-selected products are commonly referred to as time-of-flight (TOF) distributions. The $N(t)$ distributions may be converted to a probability density distributions as a function of the translational energy of the scattered product, $P\left(E_{T}\right)$, by a standard transformation. ${ }^{60}$ The $P\left(E_{T}\right)$ distributions are proportional to flux, so the total relative product flux at a given $\theta_{f}$ was determined by integrating the $P\left(E_{T}\right)$ distribution corresponding to that angle. The distribution of product flux as a function of $\theta_{f}$ (typically referred to as an "angular distribution" of product flux) can thus be obtained from the $P\left(E_{T}\right)$ distributions at each $\theta_{f}$.

It was important for the surface to be as representative as possible of a practical surface in VLEO during the molecular beam-surface scattering experiment, in order to ensure that the observed scattering dynamics reflected the scattering under realistic conditions. Samples were held at room temperature, and 
beam-surface scattering experiments were performed on surfaces that were "bathed" in $\mathrm{O}$ atoms from a low-pressure RF plasma source that produced an effusive oxygen beam with an $\mathrm{O}: \mathrm{O}_{2}$ mole ratio of approximately 30:70 and a temperature of $\sim 400 \mathrm{~K}$. Bathing surfaces with thermal atomic oxygen (with a flux estimated to be 100-1000 monolayers per second) keeps the surfaces free of contamination and ensures that there is always a high oxygen coverage, as there would be on satellite surfaces in VLEO. The pressure of the vacuum chamber was $\sim 2 \times 10^{-7}$ Torr during an experiment, and this chamber was pumped by cryopumps and an additional liquid nitrogen cooled panel in order to minimize hydrocarbon contamination. When data collection commenced, the hyperthermal $\mathrm{O} / \mathrm{O}_{2}$ beam was allowed to bombard the surface at $\theta_{i}$ $=70^{\circ}$, and data were collected over the range of final angles, $30^{\circ} \leq \theta_{f} \leq 85^{\circ}$, where positive final angles are on the opposite side of the surface normal from the incident beam. The minimum $\theta_{f}$ was limited to $30^{\circ}$ by the presence of the RF plasma source. TOF distributions of inelastically scattered $\mathrm{O}$ and $\mathrm{O}_{2}$, detected at mass-to charge ratios of $\mathrm{m} / \mathrm{z}=16\left(\mathrm{O}^{+}\right)$and $32\left(\mathrm{O}_{2}{ }^{+}\right)$, respectively, were collected in $5^{\circ}$ increments over the entire angular range. In order to average out any potential long-term drifts in experimental parameters, TOF distributions were accumulated for 500 beam pulses at each $\theta_{f}$ as the angle was incremented from the lowest value to the highest value and then decremented from the highest value to the lowest value; then this process was repeated until four TOF distributions were collected at each $\theta_{f}$. After data collection, the TOF distributions that were collected at each $\theta_{f}$ were summed, and then these summed distributions were analyzed.

Five sample surfaces based on POSS-polyimide substrates were used for the molecular beamsurface scattering experiments. One sample was used in its pristine state, and the other four were first exposed to the AO beam for 450,000 pulses, as described in Section 2.1 (see Fig. 5). The samples were (1) unexposed $\mathrm{Al}_{2} \mathrm{O}_{3}$ ALD-coated Novastrat ${ }^{\circledR}$, (2) exposed $\mathrm{Al}_{2} \mathrm{O}_{3}$ ALD-coated Novastrat ${ }^{\circledR}$, (3) exposed uncoated Novastrat ${ }^{\circledR}$, (4) exposed $\mathrm{Al}_{2} \mathrm{O}_{3}$ ALD-coated CORIN ${ }^{\circledR}$, and (5) exposed uncoated $\mathrm{CORIN}^{\circledR}$. Samples (1) and (2) allowed the investigation of the effects of AO exposure on a coated surface, while sample pairs $(2,3)$ and $(4,5)$ allowed the differences in scattering dynamics on AO-exposed coated and uncoated surfaces to be quantified. Note that the AO effects on uncoated CORIN ${ }^{\circledR}$ were studied in detail 
previously in our laboratory, ${ }^{32}$ although the sample material from the previous experiment came from a different batch that represented commercial $\mathrm{CORIN}^{\circledR}$ and was not prepared as a relatively thick and largediameter film as that used for the present study.

A separate molecular beam-surface scattering experiment was conducted on a reference singlecrystal $\mathrm{Al}_{2} \mathrm{O}_{3}$ (i.e., sapphire) surface, in order to provide a comparison between the scattering dynamics on a smooth and well-characterized $\mathrm{Al}_{2} \mathrm{O}_{3}$ surface and the amorphous $\mathrm{Al}_{2} \mathrm{O}_{3}$ ALD surfaces on rougher polymer substrates. An R-plane sapphire wafer was produced by Kyocera using a technique known as "edge-fed growth." It was polished on one side to a semiconductor grade finish. The wafer was $150 \mathrm{~mm}$ diameter and $625 \mu \mathrm{m}$ thick, and it was diced into pieces that were $25 \mathrm{~mm}$ long $\times 8 \mathrm{~mm}$ wide. The sample used for the current investigation was taken from a region near the center, which did not include the edge of the wafer. The first step in the preparation of the surface for this experiment was to expose it to the hyperthermal O-atom beam in the source chamber (Fig. 4). The translational energy distributions of the $\mathrm{O}$ and $\mathrm{O}_{2}$ components of the beam were similar to those shown in Fig. 6b, but the $\mathrm{O}: \mathrm{O}_{2}$ mole ratio was 97:3. The duration of this exposure was 50,000 pulses of the beam, or about seven hours. Based on several previous experiments in our laboratory, we may conclude that the dose of hyperthermal $\mathrm{O}$ atoms $(>1 \times$ $10^{20} \mathrm{O}$ atoms $\mathrm{cm}^{-2}$ ) was sufficient to remove $\sim 3 \mu \mathrm{m}$ of a hydrocarbon polymer and $\sim 30 \mathrm{~nm}$ of diamond. Thus, even if any residual diamond grains had been left on the surface after polishing, they should have been removed by the $\mathrm{AO}$ exposure. Furthermore, by conducting a pre-exposure to a beam of $\mathrm{O}$ atoms, the surface would be prepared as it would if it were exposed to a LEO environment. After the exposure to hyperthermal $\mathrm{O}$ atoms, the sample was removed from the source chamber and inserted into the heated sample holder, where it became the "target surface" in the main scattering chamber (see Fig. 6a). The sample was held at $677 \mathrm{~K}$, in order to minimize deposition of contamination in the high vacuum scattering chamber. No data were collected until the sample had been held at $677 \mathrm{~K}$ in the vacuum chamber overnight. When data collection commenced, the hyperthermal O-atom beam was allowed to bombard the surface at $\theta_{i}=70^{\circ}$, and TOF distributions were collected at $m / z=16\left(\mathrm{O}^{+}\right), 17\left(\mathrm{OH}^{+}\right), 32\left(\mathrm{O}_{2}^{+}\right)$, and $44\left(\mathrm{CO}_{2}^{+}\right)$. While we desired to obtain the scattering dynamics for $\mathrm{O}$ and $\mathrm{O}_{2}$, we also monitored signals associated with $\mathrm{OH}$ 
and $\mathrm{CO}_{2}$ as these are expected to be present if there is hydrocarbon contamination on the surface (from reactive scattering of the incident $\mathrm{O}$ atoms). Data were collected over the whole range of accessible final angles $\left(-20^{\circ}<\theta_{f}<85^{\circ}\right)$ until the angular distribution did not change with time and the signals from $\mathrm{OH}$ and $\mathrm{CO}_{2}$ were only a few percent of the signal from inelastically scattered $\mathrm{O}$. After a steady state was reached with a clean sapphire sample surface, TOF distributions for all four products were collected in $5^{\circ}$ increments over the entire angular range, with two passes over this range to average out any potential longterm drifts in experimental parameters. TOF distributions were accumulated for 400 beam pulses at each $\theta_{f}$ as the angle was incremented from the lowest value to the highest value and then decremented from the highest value to the lowest value; then this process was repeated until four TOF distributions were collected at each $\theta_{f}$. After data collection, the TOF distributions that were collected at each $\theta_{f}$ were summed, and then these summed distributions were analyzed.

\subsection{Particle simulations of satellite drag}

The molecular beam scattering data were used directly within state-of-the-art particle simulations capable of accurately predicting the drag for a representative satellite geometry. In order to quantify the reduction in drag (and equivalent increase in satellite orbital lifetime) realistic on-orbit conditions must be simulated, including density, temperature, and atmospheric composition. The gas flow around the satellite does not behave as a continuum fluid, rather it is highly rarefied and essentially free-molecular flow. Thus, the direct simulation Monte Carlo (DSMC) method was used. ${ }^{60-62}$ The DSMC method tracks a representative number of gas molecules through a computational domain allowing collisions with other molecules and with surfaces. Because the properties of particles impacting surfaces are directly computed by DSMC, physically realistic boundary conditions may be implemented. Diffuse scattering and full thermal accommodation (to a set wall temperature) are typical boundary conditions applied to DSMC particles. However, well-established boundary conditions also exist for surfaces that promote partial specular 
scattering and/or partial thermal accommodation. Heat transfer and shear stress to a surface are then simply computed by the respective change in energy and momentum of molecules during a surface collision.

\section{Results and Discussion}

\subsection{Surface characterization and AO exposure phenomenology}

Representative AFM images of polished sapphire (R-Plane), Nexolve Novastrat ${ }^{\circledR} 905$ blended with 7.2 wt $\%$ $\mathrm{Si}_{7} \mathrm{O}_{9}$ TSP POSS, and NeXolve CORIN ${ }^{\circledR}$ are shown in Fig. 7. The sapphire surface was much smoother
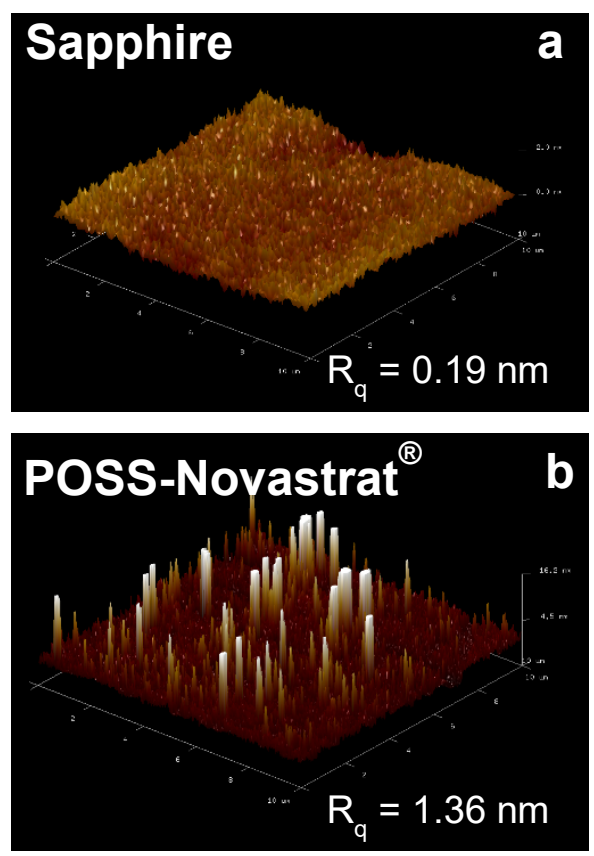

Figure 7. Representative AFM images $(10 \times 10 \mu \mathrm{m})$ of three sample surfaces. (a) R-plane surface of polished sapphire, maximum z scale $=2 \mathrm{~nm}$. (b) Nexolve Novastrat ${ }^{\circledR} 905$ blended with $7.2 \mathrm{wt} \% \mathrm{Si}_{7} \mathrm{O}_{9}$ TSP POSS, maximum z scale $=16.2 \mathrm{~nm}$. (c) and NeXolve CORIN ${ }^{\circledR}$, maximum z scale $=10.5 \mathrm{~nm}$. RMS surface roughnesses $\left(R_{q}\right)$ corresponding to each image are shown.

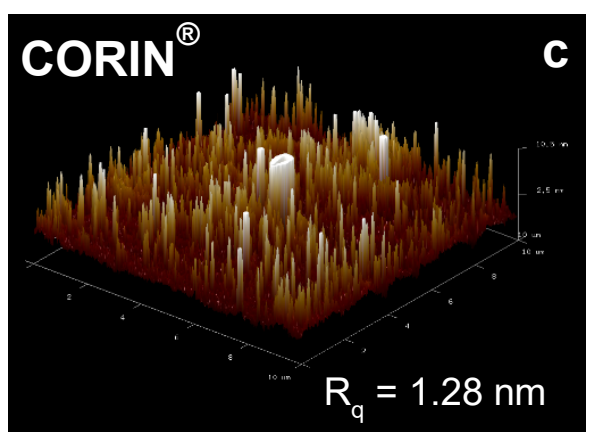

than those of POSS-Novastrat ${ }^{\circledR}$ and CORIN ${ }^{\circledR}$, with low frequency undulations in the surface, as may be seen in Fig. 7a. The POSS-Novastrat ${ }^{\circledR}$ and CORIN ${ }^{\circledR}$ surfaces exhibited many sharp features with heights that exceed the scale of the images. Many areas on all three surfaces were imaged, and the sapphire surface 
consistently appeared similar to Fig. 7a, whereas the POSS-Novastrat ${ }^{\circledR}$ and CORIN ${ }^{\circledR}$ surfaces varied significantly from area to area. On these POSS-polymer surfaces, the $\mathrm{R}_{\mathrm{q}}$ values were typically between 1 and $2 \mathrm{~nm}$ but sometimes were as high as $\sim 3 \mathrm{~nm}$. Although the POSS-polymer surfaces were clearly rough on an atomic scale, no attempt was made to investigate the relationship between processing conditions and surface roughness. The surfaces used were thus taken to be representations of those of POSS-polymers that could be produced under realistic conditions without any optimization. The $\mathrm{Al}_{2} \mathrm{O}_{3} \mathrm{ALD}$-coatings on the POSS Novastrat ${ }^{\circledR}$ and CORIN ${ }^{\circledR}$ surfaces were $10 \mathrm{~nm}$ thick and were conformal, causing a thickening of the thin "spikes" and a slight smoothing of the small features. The $\mathrm{R}_{\mathrm{q}}$ values of the ALD-coated surfaces were generally in the range of 2-3 nm, but as with the uncoated surfaces there was considerable variability from one area to the next.

Representative SEM images (10 kx magnification) of AO-exposed coated and uncoated POSSNovastrat ${ }^{\circledR}$ and CORIN ${ }^{\circledR}$ surfaces are shown in Fig. 8. These images clearly indicate that the $\mathrm{Al}_{2} \mathrm{O}_{3}$ ALD coating protected the surfaces from AO attack, except in the vicinity of coating defects. The AO erosion
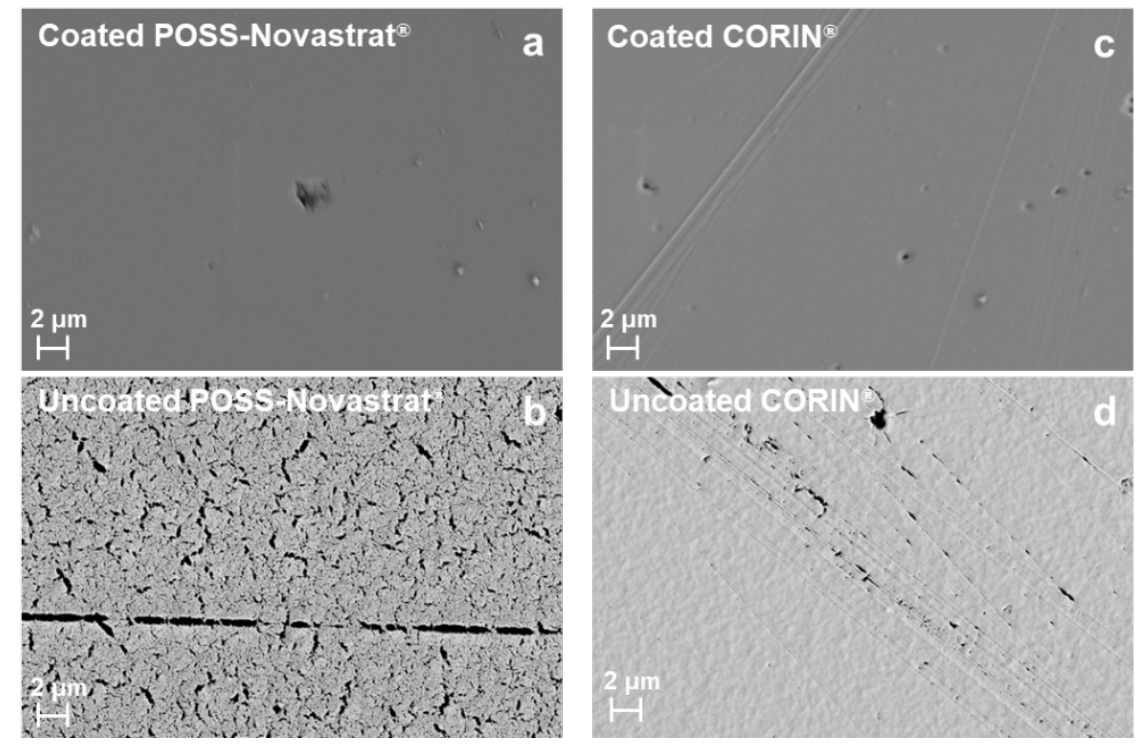

Figure 8. Representative SEM images (10 kx magnification) of coated and uncoated samples that were exposed to 450,000 pulses of the AO beam. (a) $\mathrm{Al}_{2} \mathrm{O}_{3}$-coated Nexolve Novastrat ${ }^{\mathbb{B}} 905$ blended with 7.2 wt\% $\mathrm{Si}_{7} \mathrm{O}_{9}$ TSP POSS. (b) Uncoated Nexolve Novastrat ${ }^{\circledR} 905$ blended with 7.2 wt\% Sit $\mathrm{O}_{9}$ TSP POSS. (c) $\mathrm{Al}_{2} \mathrm{O}_{3}$-coated Nexolve CORIN ${ }^{\circledR}$. (d) Uncoated NeXolve CORIN ${ }^{\circledR}$.

yields of the $\mathrm{Al}_{2} \mathrm{O}_{3}$ ALD-coated samples were unmeasurable and may be considered to be zero. On the other hand, the erosion yields of the uncoated samples could be determined from their step heights, measured by profilometry. As seen in Fig. 5b,d, uncoated POSS-Novastrat ${ }^{\circledR}$ and CORIN ${ }^{\circledR}$ samples were 
exposed side-by-side with Kapton $\mathrm{H}$ reference samples, allowing the Kapton-referenced erosion yields of these materials to be determined. For the POSS-Novastrat ${ }^{\circledR}$ sample, the measured etch depth was $1.40 \pm$ $0.20 \mu \mathrm{m}$ and the corresponding Kapton $\mathrm{H}$ reference sample had an etch depth of $37.01 \pm 0.32 \mu \mathrm{m}$. For the $\mathrm{CORIN}^{\circledR}$ sample, the measured etch depth was $0.48 \pm 0.07 \mu \mathrm{m}$ and the corresponding Kapton $\mathrm{H}$ reference sample had an etch depth of $42.58 \pm 0.53 \mu \mathrm{m}$. In terms of Kapton-referenced erosion yields ${ }^{20}$ the results for POSS-Novastrat ${ }^{\circledR}$ and CORIN ${ }^{\circledR}$ are $1.13 \pm 0.16 \times 10^{-25} \mathrm{~cm}^{3}$ O-atom ${ }^{-1}$ and $3.38 \pm 0.11 \times 10^{-26} \mathrm{~cm}^{3} \mathrm{O}$ atom $^{-1}$, respectively. The latter value may be compared with the erosion yield, $2.05 \pm 0.53 \times 10^{-26} \mathrm{~cm}^{3}$ O-atom ${ }^{-1}$, that we determined for commercially-prepared CORIN ${ }^{\circledR}$ in a recent study. ${ }^{32}$ The customsynthesized CORIN ${ }^{\circledR}$ used in this study apparently has a slightly higher erosion yield than the commercially-prepared $\mathrm{CORIN}^{\circledR}$ used in the previous study; however, we have not attempted to evaluate the differences in processing conditions that might have led to the observed difference in erosion yields. Although not shown, the AFM analysis of the $\mathrm{Al}_{2} \mathrm{O}_{3}$ ALD-coated samples indicated that their surfaces remained unchanged after $\mathrm{AO}$ exposure. The surfaces of the exposed samples were too rough to be characterized accurately by AFM. As may be seen in the SEM images in Fig. 8, the exposed CORIN ${ }^{\circledR}$ did not become as rough as the POSS-Novastrat ${ }^{\circledR}$ surface during AO exposure, consistent with our previous study. ${ }^{32}$

Several features of the SEM images in Fig. 8 suggest that the sample surfaces prepared for the present studies had defects. The $\mathrm{Al}_{2} \mathrm{O}_{3}$ ALD-coated POSS-Novastrat ${ }^{\circledR}$ surface in Fig. 8a shows an example of a pit, of which several were observed in various images that were collected. This pit may have been caused by erosion at a defect, but more likely it was a defect that had been coated. Although not shown, such defects were observed on the pristine POSS-Novastrat ${ }^{\circledR}$ surfaces but were not present on the surfaces of pristine Kapton $\mathrm{H}$ or on $\mathrm{Al}_{2} \mathrm{O}_{3}$ ALD-coated Kapton $\mathrm{H}$ surfaces. The AO-exposed, uncoated POSSNovastrat $^{\circledR}$ surface exhibited a morphology similar to what has been observed on POSS-PMDA-ODA polyimide blends. ${ }^{31,32}$ In addition, some lines of erosion were observed (e.g., Fig. 8b), which were not observed in the previous studies. Interestingly, no evidence of lines or ridges were observed on the surfaces 
of the pristine POSS-Novastrat ${ }^{\circledR}$ samples. On the other hand, ridges were observed on both the pristine and AO-exposed CORIN ${ }^{\circledR}$ surfaces (Fig. 8d), as well as on the exposed $\mathrm{Al}_{2} \mathrm{O}_{3}$ ALD-coated CORIN ${ }^{\circledR}$ surfaces (Fig. 8c). Such ridges were not observed on any of the $\mathrm{CORIN}^{\circledR}$ surfaces that were investigated in our previous study that used commercially-prepared CORIN ${ }^{\circledR}$. It is possible that the preparation method used for the large-diameter and relatively thick films for the present study yielded films that were not homogeneous, suggested by the observation that both the POSS-Novastrat ${ }^{\circledR}$ and CORIN ${ }^{\circledR}$ surfaces seem to erode preferentially along ridges or lines. The origin of these observations is currently unknown, but one would expect that refinement in the processing of these materials would result in films that do not contain pits and ridges on their surfaces and that erode in a uniform fashion. Nevertheless, the uncoated materials showed extremely low erosion yields of $1-4 \%$ that of Kapton $\mathrm{H}$, and a $\sim 10 \mathrm{~nm}$ coating of $\mathrm{Al}_{2} \mathrm{O}_{3}$ completely protected these films from attack by hyperthermal oxygen atoms. Thus, the coating has been demonstrated to protect against AO attack, and the POSS-containing polymer substrate has been demonstrated to be highly AO resistant. Furthermore, the coating appears to be strongly adherent to the substrate and does not show signs of cracking and other wide-spread defects.

\subsection{Scattering dynamics}

The primary data for investigating the scattering dynamics of $\mathrm{O}$ and $\mathrm{O}_{2}$ on the various surfaces were TOF distributions, which were collected with $\theta_{i}=70^{\circ}$ and with a variety of $\theta_{f}$ angles. Representative TOF distributions are displayed in Figs. 9-11. These distributions may be described in terms of two limiting cases of impulsive scattering (IS) and thermal desorption (TD), as has been discussed in many previous publications. ${ }^{19,37,39-44,56,57,59,61}$ The signals indicate that $\mathrm{O}$ atoms scattered only impulsively (IS) from the sapphire and AO-exposed and coated POSS-Novastrat ${ }^{\circledR}$ and CORIN ${ }^{\circledR}$ surfaces. The uncoated surfaces of AO-exposed POSS-Novastrat ${ }^{\circledR}$ and CORIN $^{\circledR}$ showed a dominant IS component, but there was also a discernable TD component, indicative of "diffuse scattering" on a rough surface. The fraction of TD was higher from POSS-Novastrat ${ }^{\circledR}$ than from CORIN ${ }^{\circledR}$, suggesting that the surface of uncoated POSS- 
Novastrat ${ }^{\circledR}$ became rougher than that of CORIN $^{\circledR}$ during the $\mathrm{AO}$ exposure, which is consistent with the SEM data (Fig. 8b,d).

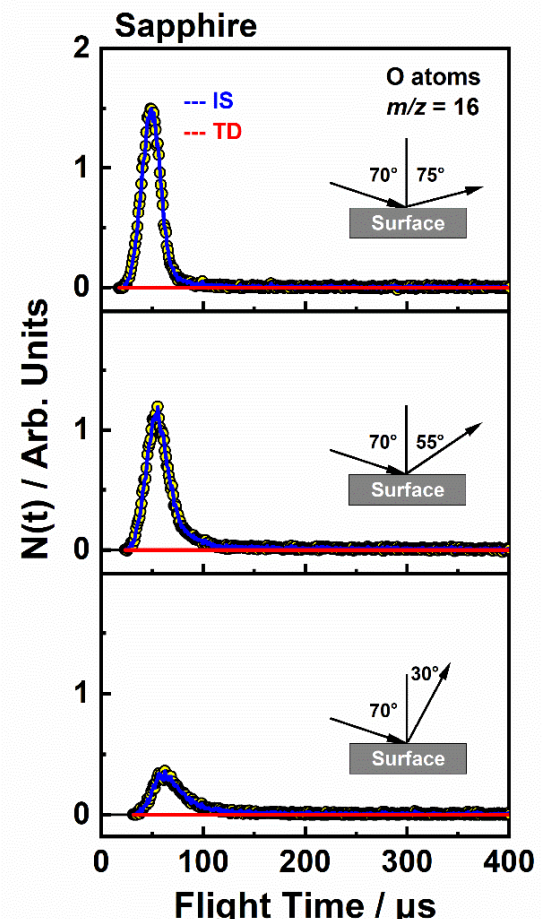

Figure 9. Representative time-of-flight (TOF) distributions for $O$ atoms (detected at $m / z=16$ ) that scattered from the sapphire surface (R-plane) following impingement of $O$ atoms with an average incident energy of $\langle E i\rangle=506 \mathrm{~kJ} \mathrm{~mol}^{-1}$ at $\theta_{\mathrm{i}}=70^{\circ}$.
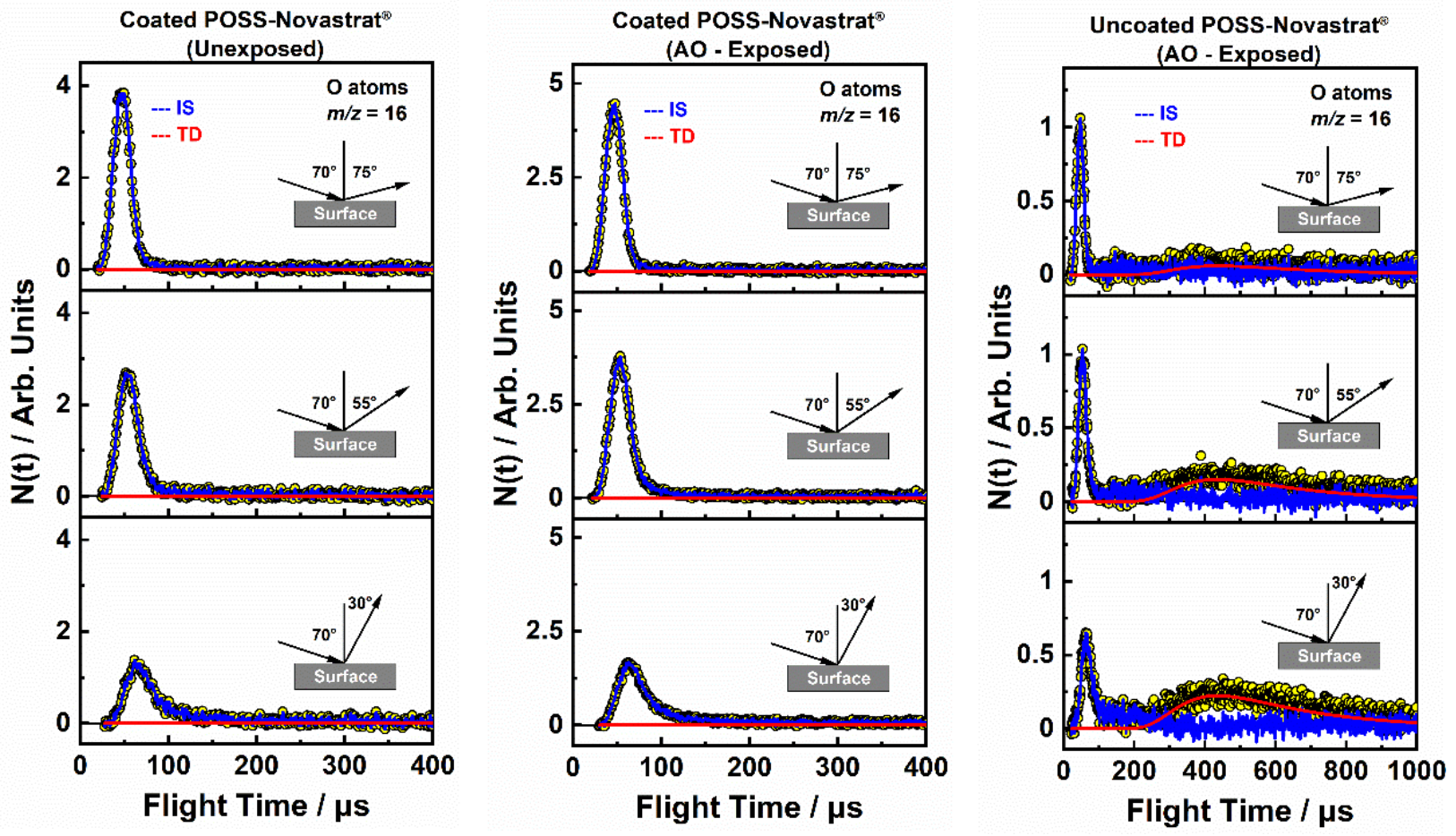

Figure 10. Representative time-of-flight (TOF) distributions for $O$ atoms (detected at $m / z=16$ ) that scattered from various POSS-Novastrat ${ }^{\circledast}$ surfaces, as indicated, following impingement of $O$ atoms with an average incident energy of $\langle E i\rangle=498 \mathrm{~kJ} \mathrm{~mol}^{-1}$ at $\theta_{1}=70^{\circ}$. 

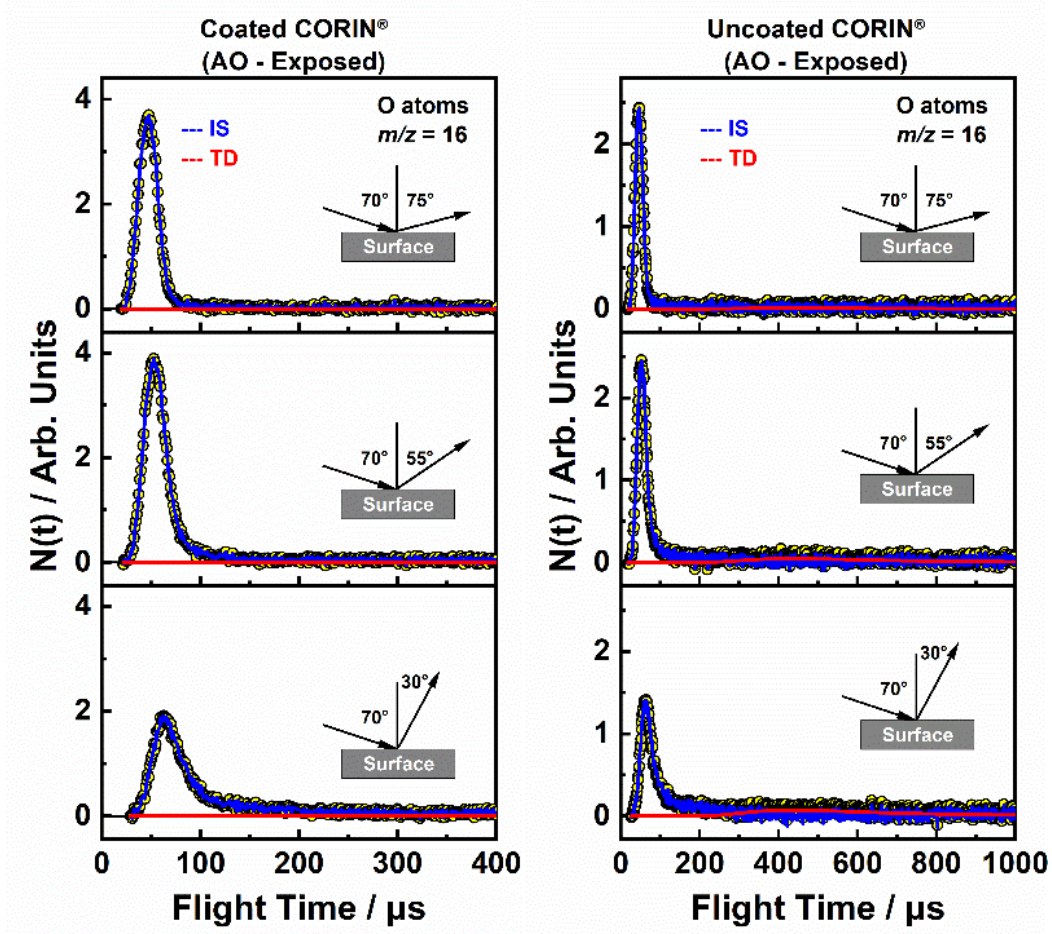

Figure 11. Representative time-of-flight (TOF) distributions for $O$ atoms (detected at $m / z=16$ ) that scattered from AO-exposed coated and uncoated CORIN ${ }^{\circledR}$ surfaces, as indicated, following impingement of $O$ atoms with an average incident energy of $\langle E i\rangle=498 \mathrm{~kJ} \mathrm{~mol}^{-1}$ at $\theta_{i}=70^{\circ}$.

The experimental TOF distributions, including both the IS and TD components, were integrated to obtain relative flux and average final translational energy for $\mathrm{O}$ atoms scattered at each final angle, $\theta_{f}{ }^{57}$ The angular distributions for O-atom scattering on all surfaces are compared in Fig. 12, where the distributions have been normalized to the same maximum value. All distributions had a lobular shape, with maxima in the forward scattering direction, far from the surface normal. Such angular distributions are characteristic of scattering in the structure regime. ${ }^{36}$ Under the conditions of these experiments, where the incident energy is much higher than the well depth of the physisorption potential (expected to be $<<100 \mathrm{~kJ}$ $\mathrm{mol}^{-1}$ ), the shape of the angular distribution provides an indication of the relative roughness of the surface with respect to hyperthermal O-atom scattering. ${ }^{44}$ In particular, a narrower angular distribution suggests a smoother surface. A maximum at a larger final angle is a signature of a smoother surface, too, although the 


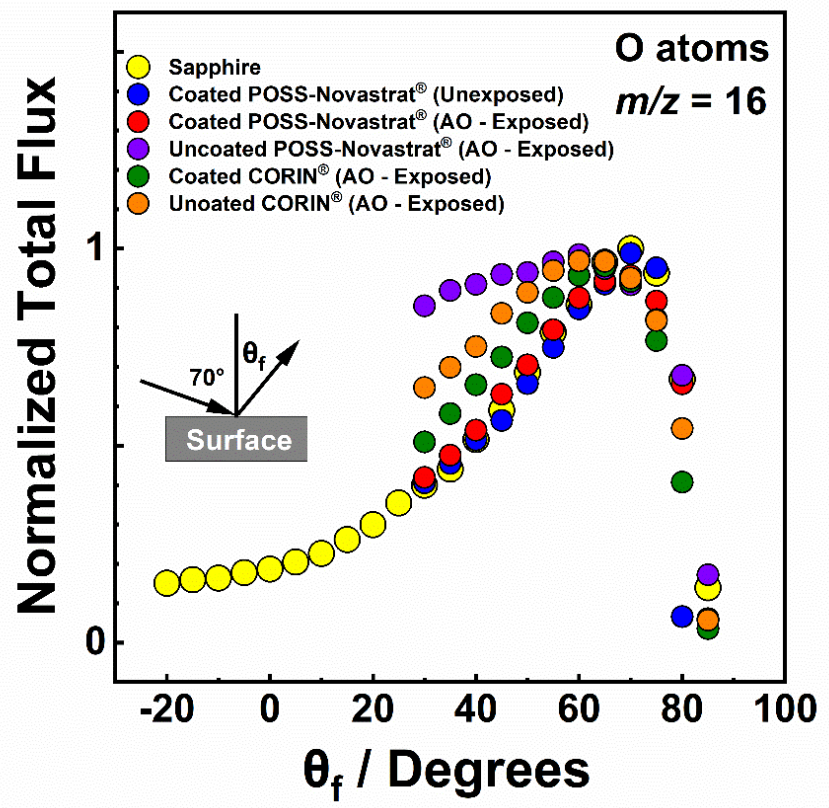

Figure 12. Angular distributions of total scattered $O$ atom flux from all surfaces investigated, as a function of final angle $\left(\theta_{f}\right)$, following impingement of $O$ atoms at $\theta_{1}=70^{\circ}$ with $\left\langle E_{i}\right\rangle=506 \mathrm{~kJ} \mathrm{~mol}^{-1}$ on sapphire and $\left\langle E_{i}\right\rangle=498 \mathrm{~kJ} \mathrm{~mol}^{-1}$ on all other surfaces. All distributions have been normalized to a maximum value of 1.0. The experimental scattering measurements were made in the plane defined by the incident beam and the surface normal.

relative width of the angular distribution is a less subtle signature. The narrowest angular distribution corresponds to O-atom scattering from the sapphire and coated POSS-Novastrat ${ }^{\circledR}$ surfaces, whereas the angular distribution is significantly broader for O-atom scattering from AO-exposed uncoated $\mathrm{CORIN}^{\circledR}$ and broader still for scattering from AO-exposed uncoated POSS-Novastrat ${ }^{\circledR}$. These results are consistent with the AFM and SEM measurements. It is curious that the distribution for $\mathrm{O}$ atoms that scattered from AOexposed coated CORIN ${ }^{\circledR}$ is slightly broader than those for both coated POSS-Novastrat ${ }^{\circledR}$ samples. It is possible that surface defects on the $\mathrm{CORIN}^{\circledR}$ surface before the coating was applied may have played a roll in the effective surface roughness, but we have insufficient information to speculate further. The TOF and angular distributions for coated POSS-Novastrat ${ }^{\circledR}$ were essentially identical before and after the AO exposure, providing further evidence that $\mathrm{AO}$ bombardment had no effect on the effective roughness of the $\mathrm{Al}_{2} \mathrm{O}_{3}$ ALD-coated POSS-Novastrat ${ }^{\circledR}$ surface.

In addition to the distribution of scattering angles, the average energy (or momentum) transfer associated with gas-surface collisions has an important effect on satellite drag. The average energy transfers for O-atom collisions on the surfaces investigated are represented by plots of the ratio of average final energy to average incident energy, $\left\langle E_{f}\right\rangle\left\langle\left\langle E_{i}\right\rangle\right.$, as a function of $\theta_{f}$, as shown in Fig. 13. It can be seen that $\mathrm{O}$ atoms with grazing scattering trajectories $\left(\theta_{f}>60^{\circ}\right)$, which are most probable for coated materials, retain 
$>80 \%$ of their translational energy after scattering. The energy ratios as a function of $\theta_{f}$ are nearly identical for $\mathrm{O}$ atoms that scatter on all surfaces except for AO-exposed uncoated POSS-Novastrat ${ }^{\circledR}$, which shows significantly higher energy transfer (i.e., lower $\left\langle E_{f}\right\rangle\left\langle\left\langle E_{i}\right\rangle\right)$. Higher energy transfer is consistent with the observation that AO-exposed uncoated POSS-Novastrat ${ }^{\circledR}$ has a significantly rougher surface than those of all other samples, because a rougher surface is expected to lead to more multiple-bounce scattering on the surface and therefore more chances for energy to be transferred to the surface. The observation of similar energy transfers for the other samples provides an indication of the sensitivity of surface roughness to energy transfer, where it appears that O-atom-surface energy transfer on these surfaces may be relatively insensitive to rms roughnesses that are less than approximately $10 \mathrm{~nm}$.

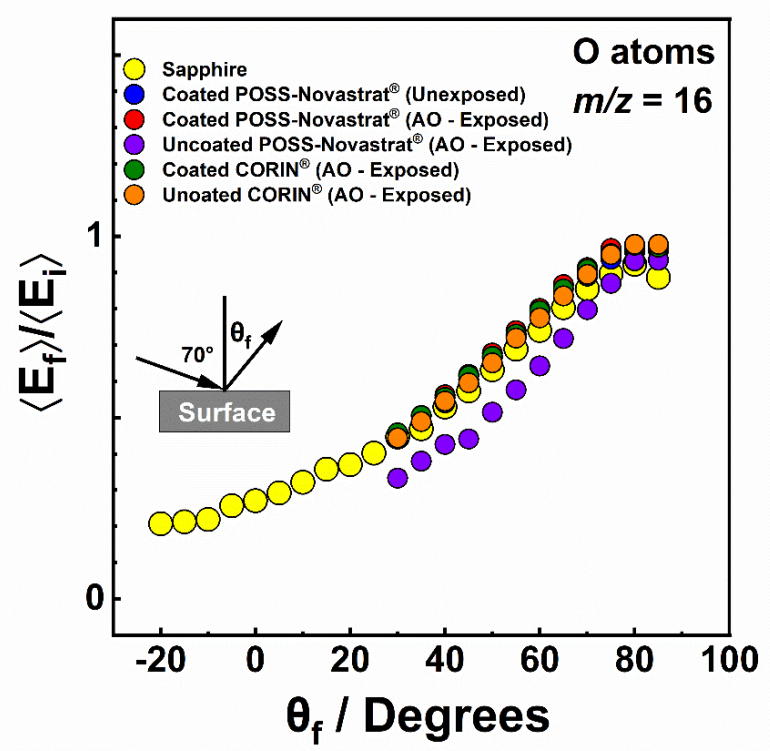

Figure 13. Angular dependence of $\left\langle E_{f}\right\rangle /\left\langle E_{i}\right\rangle$ for the $O$ atoms that scattered from the various surfaces with $\theta_{i}=$ $70^{\circ}$. $\left\langle E_{i}\right\rangle$ for $O$ on sapphire was $506 \mathrm{~kJ} \mathrm{~mol}^{-1}$, and $\left\langle E_{i}\right\rangle$ for $\mathrm{O}$ on all other surfaces was $498 \mathrm{~kJ} \mathrm{~mol}^{-1}$.

The scattering dynamics of $\mathrm{O}_{2}$ were also investigated on all surfaces; however, the use of the $\mathrm{RF}$ oxygen plasma source resulted in a high background of $\mathrm{O}_{2}$ in the detector, making the data noisy and unreliable for $\mathrm{O}_{2}$ scattering from all surfaces except sapphire, for which the RF plasma source was not used. The angular distributions and energy ratios for $\mathrm{O}_{2}$ scattering on sapphire, analogous to the data presented in Figs. 12 and 13, are shown in Fig. 14. The angular distribution for $\mathrm{O}_{2}$ scattering on sapphire is nearly identical to that for $\mathrm{O}$ scattering from sapphire (Fig. 12). In addition, the energy ratio, $\left\langle E_{f}\right\rangle /\left\langle E_{i}\right\rangle$, as a function of $\theta_{f}$, for $\mathrm{O}_{2}$ scattering from sapphire is very similar to that for $\mathrm{O}$ scattering from sapphire. Because most of the flux tends to appear at large final angles, the energy ratio, when weighted by total (in-plane) scattered 
flux, is 0.64 for $\mathrm{O}$ and 0.61 for $\mathrm{O}_{2}$. Given the strong similarity in the scattering dynamics for $\mathrm{O}$ and $\mathrm{O}_{2}$ on sapphire, we assume that the analogous scattering dynamics of $\mathrm{O}$ and $\mathrm{O}_{2}$ on the other surfaces investigated are also similar.
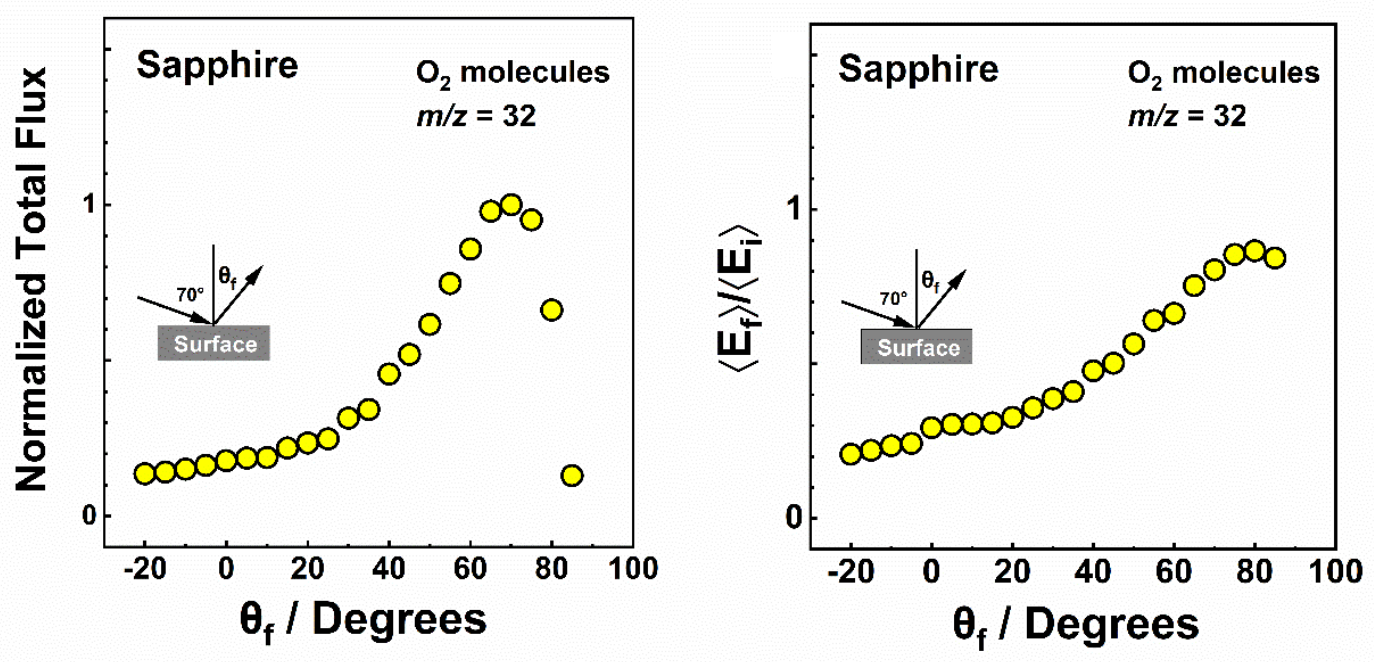

Figure 14. (left) Angular distribution of scattered $O_{2}$ flux from sapphire, with $\left\langle E_{i}\right\rangle=1012 \mathrm{~kJ} \mathrm{~mol}^{-1}$ at $\theta_{i}=70^{\circ}$. (right) Ratio of average final energy, $\left\langle E_{f}\right\rangle$, to average incident energy, $\left\langle E_{i}\right\rangle$, as a function of final angle, $\theta_{f}$, for $\mathrm{O}_{2}$.

\subsection{DSMC simulations of drag}

A gas-surface scattering model is required for the boundary conditions of the DSMC simulations. Because the simulations are three-dimensional and performed for realistic atmospheric conditions (orbital velocity and thermal velocity associated with the local temperature), gas particles may strike the surface with a distribution of relative angles and velocities. Furthermore, the satellite geometry is represented in the simulations by a large number of individual triangular surface elements that have a variety of orientations with respect to the flight direction. The scattering model must therefore accommodate a wide range of incident particle velocities and any incident angle. For this work we used the well-known CLL scattering model of Cercignani, Lampis, and Lord. ${ }^{63}$ The CLL model equations used to compute the reflected particle's angles and velocity components with respect to the surface element, given the incident angles and velocity components are given in Table 1 (we follow the presentation style of Ref. ${ }^{64}$ ). 
Table 1. Model equations for the CLL gas-surface scattering model.

\begin{tabular}{|c|c|c|}
\hline Normal component & Tangential component 1 & Tangential component 2 \\
\hline$r_{1}=\sqrt{-\alpha_{n} \ln x_{1}}$ & $r_{3}=\sqrt{-\alpha_{t} \ln x_{3}}$ & $r_{5}=\sqrt{-\alpha_{t} \ln x_{5}}$ \\
\hline$\phi_{2}=2 \pi x_{2}$ & $\phi_{4}=2 \pi x_{4}$ & $\phi_{6}=2 \pi x_{6}$ \\
\hline$v_{n *}=\left|v_{n, i} / v_{m p w}\right| \sqrt{1-\alpha_{n}}$ & $v_{t *}=\left|v_{t, i} / v_{m p w}\right| \sqrt{1-\alpha_{t}}$ & --- \\
\hline$v_{n, r}=v_{m p w} \sqrt{r_{1}^{2}+v_{n *}^{2}+2 r_{1} v_{n *} \cos \phi_{2}}$ & $v_{t 1, r}=v_{m p w}\left(v_{t *}+r_{3} \cos \phi_{4}\right)$ & $v_{t 2, r}=v_{m p w} r_{5} \cos \phi_{6}$ \\
\hline
\end{tabular}

Here, $x_{i}$ are different random numbers, each uniformly distributed between 0 and 1 , and the most probable velocity based on the wall temperature $\left(T_{w}\right)$ is given by $v_{m p w}=\sqrt{2 R_{s} T_{w}}$, where $R_{s}$ is the specific gas constant for the gas particle species impacting the wall. As seen by the CLL model equations in Table 1, the normal accommodation coefficient $\left(\alpha_{n}\right)$ and tangential accommodation coefficient $\left(\alpha_{t}\right)$ are the only two model parameters required. Given the incident velocity components normal $\left(v_{n, i}\right)$, and tangential $\left(v_{t, i}\right)$, to the surface triangle plane, the equations in Table 1 are used to compute the scattered particle velocity components normal $\left(v_{n, r}\right)$, and tangential $\left(v_{t 1, r}\right.$ and $\left.v_{t 2, r}\right)$ to the surface triangle plane. These new particle velocities are then returned to the DSMC simulation for subsequent movement of the particle.
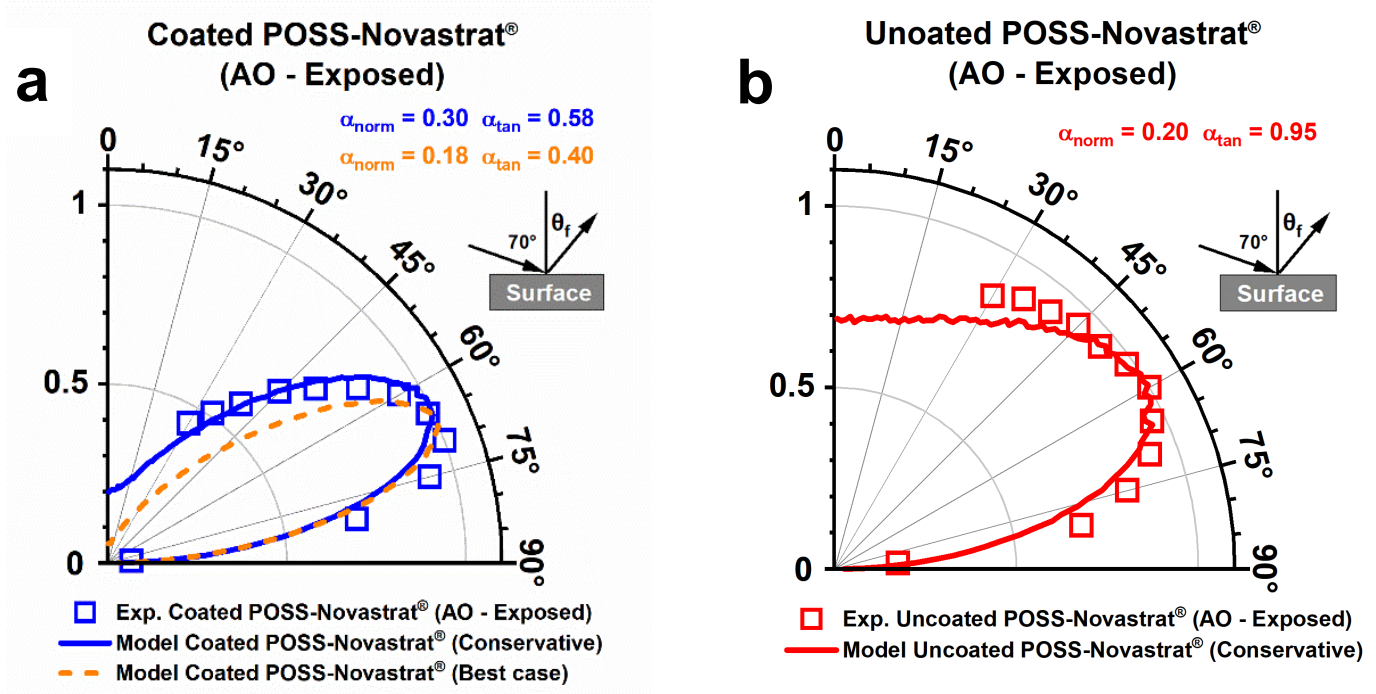

Figure 15. CLL model results compared to experimental data for (a) coated POSS-Novastrat ${ }^{\circledR}$, and $(b)$ uncoated POSSNovastrat ${ }^{\circledR}$. 
The CLL model parameters $\left(\alpha_{n}\right.$ and $\left.\alpha_{t}\right)$ were fit to match molecular beam-surface scattering results on both AO-exposed uncoated and coated POSS-Novastrat ${ }^{\circledR}$ surfaces. POSS-Novastrat ${ }^{\circledR}$ was chosen as the representative material for the DSMC simulations because the scattering dynamics on coated POSSNovastrat ${ }^{\circledR}$ were similar to those on coated CORIN $^{\circledR}$ while the difference in scattering dynamics was larger for coated and uncoated POSS-Novastrat ${ }^{\circledR}$ vs. those on coated and uncoated CORIN ${ }^{\circledR}$. Parameter optimization for POSS-Novastrat ${ }^{\circledR}$ CLL models was accomplished by performing free-molecular scattering computations where $\mathrm{O}$ atoms had an incident angle $\left(\theta_{i}=70^{\circ}\right)$ and an incident velocity (near $\left.8000 \mathrm{~m} \mathrm{~s}^{-1}\right)$, matching the molecular beam-surface scattering experiments. The CLL model was then used to compute velocities and relative angles (many thousands) of scattered $\mathrm{O}$ atoms, and the resulting distributions were compared to the experimental data as shown in Fig. 15. For coated POSS-Novastrat ${ }^{\circledR}$ (Fig. 15a), two model parameterizations were made, as the CLL model was not able to precisely match the entire experimental angular distribution. A "conservative" coated POSS-Novastrat ${ }^{\circledR}$ model $\left(\alpha_{n}=0.30, \alpha_{t}=0.58\right)$ captures the smaller-angle scattering dynamics $\left(\theta_{f}<60^{\circ}\right)$ accurately but underestimates the amount of grazing-angle scattering $\left(\theta_{f}>60^{\circ}\right)$. As grazing-angle scattering is the highest probability outcome, a "best-case" coated POSS-Novastrat ${ }^{\circledR}$ model $\left(\alpha_{n}=0.18, \alpha_{t}=0.40\right)$ was parametrized to more accurately capture the peak probability near $\theta_{f}=70^{\circ}$, but this model underestimates the amount of small-angle scattering. Figure $15 \mathrm{~b}$ shows the CLL model parametrization for uncoated POSS-Novastrat ${ }^{\circledR}\left(\alpha_{n}=0.20, \alpha_{t}=0.95\right)$, for which only one parametrization was created. It is important to note that each CLL parametrization must also reproduce the energy accommodation measured experimentally, as discussed below. While modifications to the CLL model equations could be made, the three models, whose results are shown in Fig. 15, provide an excellent representation, including a measure of uncertainty ("conservative" vs. "best-case"), in the fit to the experimental data.

While the experiments were performed for a single incident angle of $\theta_{i}=70^{\circ}$, the CLL model was applied to all possible incident angles. Figure 16 shows the "conservative" coated POSS-Novastrat ${ }^{\circledR}$ model 


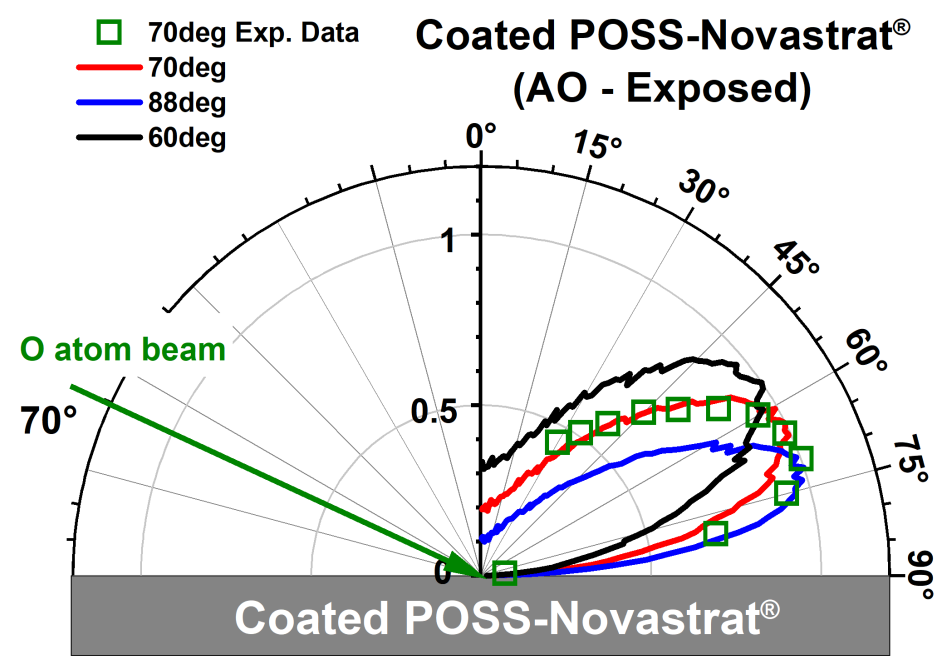

Figure 16. (a) CLL model results for the "conservative" coated POSS-Novastrat ${ }^{\circledR}$ model over a range of incident particle angles relative to the surface normal. Model results are compared to experimental data at $\theta_{1}=70^{\circ}$.

results for a range of incident angles. Although there is no data at these incident angles, the model is wellbehaved and shows the expected trend of increased forward scattering for more grazing incident angles, and increased diffuse scattering for more normal incident angles.

Energy accommodation predictions from the three CLL models are compared to the experimental data in Fig. 17a. The models accurately reproduce the experimental data, which clearly shows that coated POSS-Novastrat ${ }^{\circledR}$ has a lower energy accommodation (ratio closer to unity) compared to the uncoated POSS-Novastrat ${ }^{\circledR}$. Furthermore, the "best-case" coated POSS-Novastrat ${ }^{\circledR}$ model is seen to have the lowest energy accommodation; hence, it is expected to give the lowest drag (i.e., "best-case") result when applied to flow over a satellite. Figure $17 \mathrm{~b}$ shows the "conservative" coated POSS-Novastrat ${ }^{\circledR}$ model behavior for a range of incident angles. As expected, the ratio approaches unity when the final angle is equal to the incident angle, for each of the incident angles considered.

In order to understand how the coated POSS-Novastrat ${ }^{\circledR}$ material may lower drag for a VLEO satellite, we performed three-dimensional DSMC simulations for a representative microsatellite geometry (results shown in Figs. 18 and 19). The satellite bus is approximately $1 \mathrm{~m} \mathrm{long}, 20 \mathrm{~cm}$ wide, and $15 \mathrm{~cm}$ 

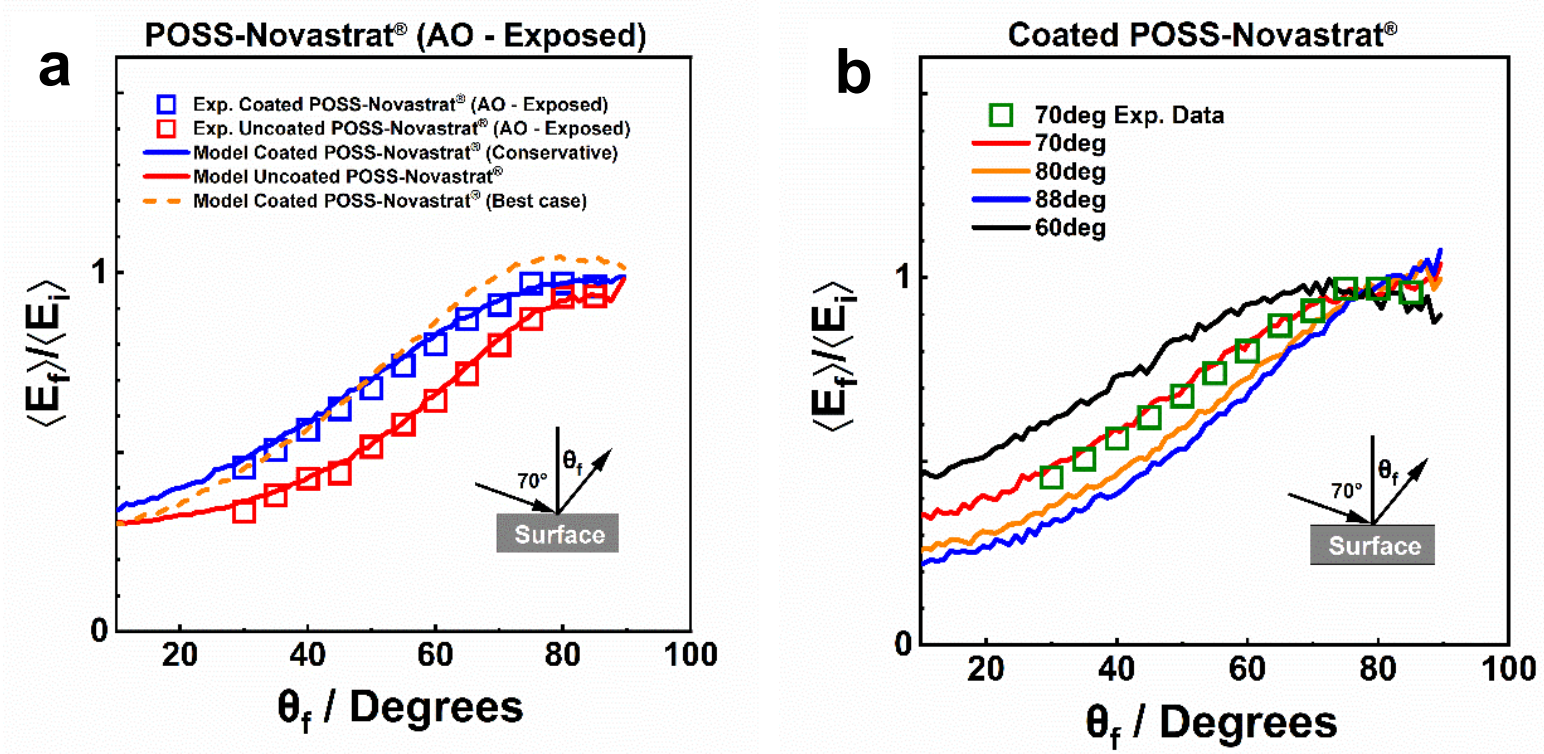

Figure 17. (a) CLL model results for energy accommodation compared to experimental data for an incident angle of $70^{\circ}$. (b) CLL model results for the "conservative" coated POSS-Novastrat ${ }^{\circledR}$ surface over a range of incident angles.

thick. Solar panels fold out from the bus such that their main surfaces are aligned parallel to the direction of motion and have a thickness of $2 \mathrm{~mm}$. The ram face of the satellite is a wedge, with a half angle of $20^{\circ}$ ( $20^{\circ}$ opposing wedge angles relative to the central plane of the bus). Simulation particles (representing atoms and molecules) are initialized to flow into the domain at free-stream conditions matching a bulk velocity of $8 \mathrm{~km} \mathrm{~s}^{-1}$, with a gas temperature of $890 \mathrm{~K}$, a gas density of $5 \times 10^{-11} \mathrm{~kg} / \mathrm{m}^{3}$, and with $\mathrm{N}_{2}, \mathrm{O}_{2}$, and $\mathrm{O}$ mass fractions of $0.355,0.022$, and 0.623 , respectively. These gas conditions correspond approximately to orbital conditions at $250 \mathrm{~km}$ altitude. Of course, atmospheric properties vary significantly over the course of many orbits and can be different for different orbital paths. Nevertheless, these conditions, along with a constant surface temperature $\left(T_{w}=300 \mathrm{~K}\right)$ were selected to produce representative drag results and were used for all simulations to ensure a fair comparison between the different material models. It is important to note that, as a result of the realistic thermal motion of particles, they will not all impact the leading edge at precisely $8 \mathrm{~km} \mathrm{~s}^{-1}$ and $70^{\circ}$ to the surface normal $\left(20^{\circ}\right.$ relative to the free stream). Instead, they will impact at a range of incident velocities and angles. Furthermore, particles will collide, at highly grazing angles, with the satellite bus and solar panel surfaces that are parallel 
to the flight direction. Finally, while many particles will collide with the satellite surface only once, particles can undergo an arbitrary number of surface collisions within these DSMC simulations. Gas-phase collisions are also enabled using standard DSMC collision models, ${ }^{62}$ however, these are extremely rare under such free-molecular-flow conditions. The DSMC simulations are highly resolved, including cell sizes far below the mean free path, time steps far below the mean collision time, and several hundred particles per cell.

Two key assumptions are made in the DSMC simulations. First, the CLL gas-surface models are based on in-plane scattering dynamics only. As the molecular beam experiment only probed the scattering dynamics in the plane defined by the incident beam and the surface normal, we chose not to assume different scattering dynamics out of this plane. If future experiments reveal that particles scatter with different behavior out of plane compared to the measured in-plane behavior, then this assumption could easily be revisited with the new data. Second, we assume that the scattering dynamics and translational energy accommodation of $\mathrm{O}_{2}$ and $\mathrm{N}_{2}$ are the same as those for $\mathrm{O}$ atoms. Specifically, the same CLL model parameters (fit to O-surface scattering data, as described above) are also used to determine the post-collision velocities for both $\mathrm{O}_{2}$ and $\mathrm{N}_{2}$ collisions with the surface. No internal energy accommodation was assumed in the CLL model simulations (given the near-specular nature of the interactions), meaning that the postcollision rotational and vibrational energies of the molecules are the same as the incident energies. As can be seen in the experimental results above, the scattering dynamics of $\mathrm{O}$ and $\mathrm{O}_{2}$ are nearly identical on sapphire and we assume they are also very similar on the other surfaces. The inelastic scattering dynamics of $\mathrm{N}_{2}$ would be expected to be essentially identical to those of $\mathrm{O}_{2}$ because their masses are similar and the interaction potentials of both molecules on the relevant surfaces are weak compared to the high incident energy. Again, this second assumption could be revisited when more experimental data become available. The average particle velocity in the $x$ direction $(V x)$ is plotted in each DSMC cell for several cases in Figs. 18 and 19, where the effects of enhanced specular scattering compared to diffuse scattering are visually portrayed. It is important to understand that, under such free-molecular-flow conditions, particle velocity distributions in each computational cell are generally bimodal. One portion of the distribution 
represents particles from the free stream that have not interacted with the surface, and another portion represents the particles that have scattered from the surface. Therefore, cells where Vx is lower than the free-stream bulk velocity are regions where scattered particles are present. For example, Fig. 18a shows the flow-field results for a DSMC simulation that assumes diffuse scattering and full thermal
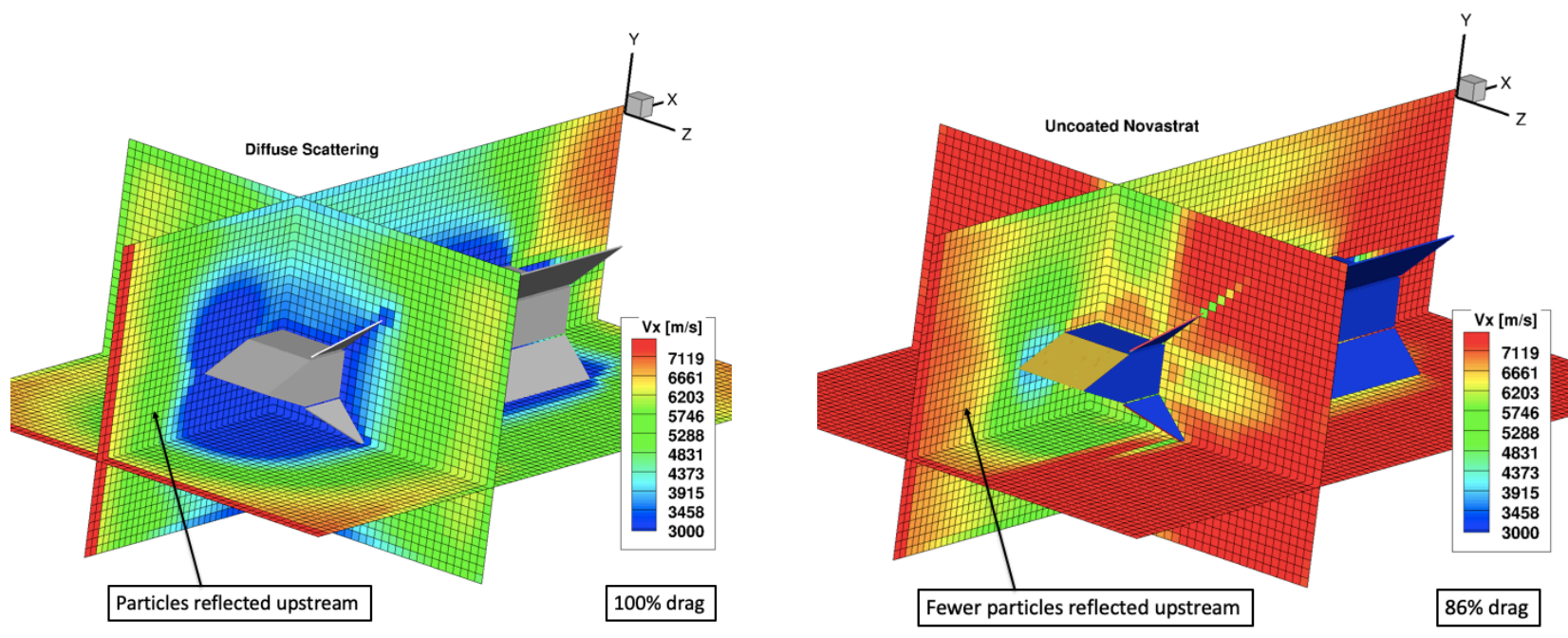

Figure 18. DSMC simulation results depicting the average particle velocity in the $x$ direction $(V x)$ in each computational cell, corresponding to (a) fully diffuse scattering and full energy accommodation, and (b) the CLL model applied to AOexposed uncoated Novastrat ${ }^{\circledR}$.
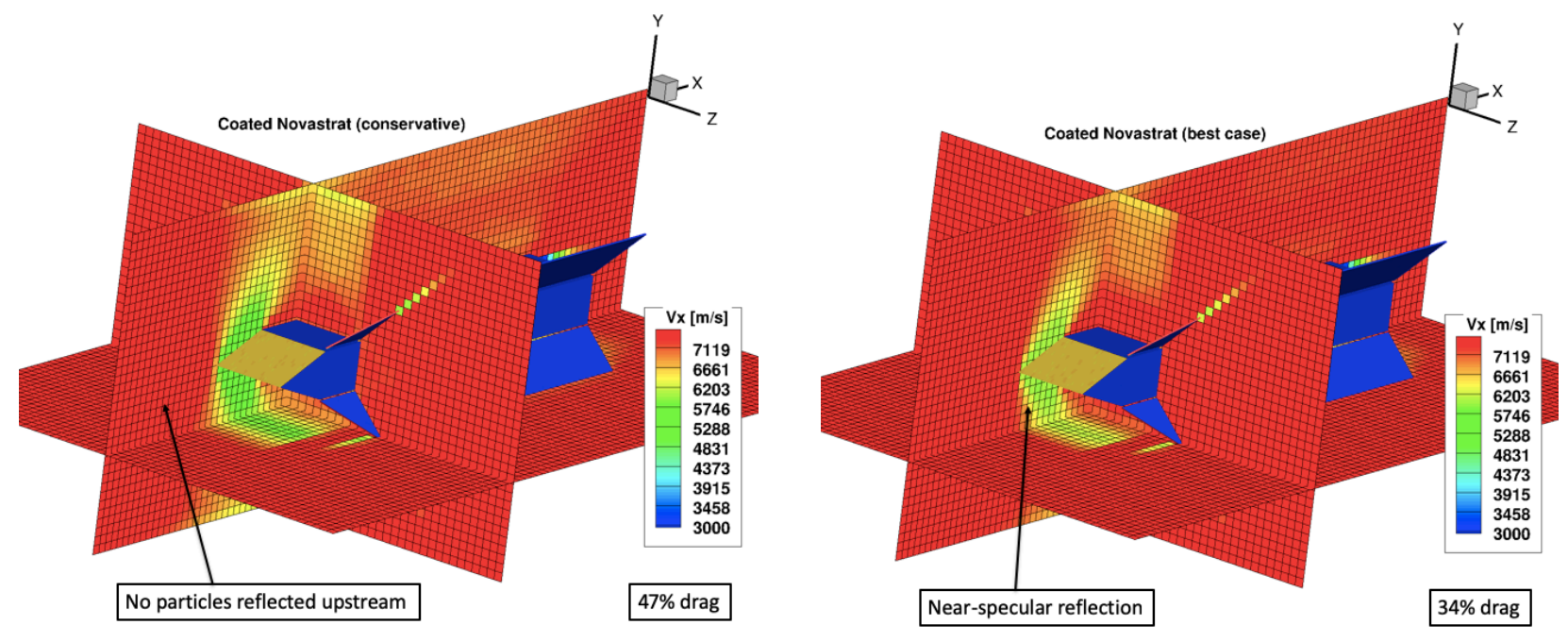

Figure 19. DSMC simulation results depicting the average particle velocity in the $x$ direction $(V x)$ in each computational cell, corresponding to (a) the "conservative" CLL model for coated Novastrat ${ }^{\circledR}$, and (b) the "best- case" CLL model for AO-exposed coated Novastrat ${ }^{\circledR}$. 
accommodation $\left(\alpha_{n}=1.0, \alpha_{t}=1.0\right)$. In this case, $V x$ is lowered significantly in the entire domain surrounding the satellite, as particles scatter diffusely from the surface and then propagate in all directions as a result of the free-molecular-flow conditions. The total net force (in the $x$-direction) resulting from particle collisions is recorded and summed across all triangulated surface elements and serves as a baseline “100\% drag” result. In Fig. 18b, the flow field result for an identical simulation, with the CLL gas-surface model parametrized for the uncoated POSS-Novastrat ${ }^{\circledR}$, is shown. The amount of diffuse scattering, especially at more grazing scattering angles, is lower than the fully diffuse result. The computed drag for this simulation is $86 \%$ of the value recorded for the baseline fully diffuse case. The results for coated POSS-Novastrat ${ }^{\circledR}$, shown in Fig. 19a ("conservative" CLL model) and in Fig. 19b ("best-case" CLL model) are dramatically different than the results in Figs. $18 \mathrm{a}$ and $18 \mathrm{~b}$. Here, the majority of cells contain $V x$ values that match the free-stream bulk velocity. Particles clearly scatter at grazing angles from the $20^{\circ}$ leading edge surfaces. During such grazing scattering, the energy accommodation and momentum transfer to the surface are quite low (refer to Fig. 17a). As a result, the drag values for the "conservative" and "best-case" coated POSS-Novastrat $^{\circledR}$ are $47 \%$ and $34 \%$, respectively, of the fully diffuse baseline value. Similar simulations (not shown) were performed for yaw and pitch angles of $5^{\circ}$, and drag was found to increase by up to 18 percent over the corresponding $0^{\circ}$ angle-of-attack simulations shown in Fig. 19, with the overall drag still much less than the baseline fully diffuse scattering result or the result from the uncoated POSSNovastrat ${ }^{\circledR}$, regardless of whether the "conservative" or "best-case" model is used for the coated POSSNovastrat $^{\circledR}$. Clearly, on a suitably-designed VLEO satellite, a robust coating that promotes grazing scattering on external materials would significantly reduce the drag compared to an uncoated material that could become rough through $\mathrm{AO}$ exposure even if it is highly AO-resistant.

\section{Conclusion}

A material with a smooth AO-resistant coating on an AO-resistant polymer substrate shows promise for use on the external surfaces of satellites in VLEO, where low drag and AO resistance are essential to 
satellite function in this relatively high density and highly corrosive environment. Test coupons of POSScontaining polyimides with and without $\mathrm{Al}_{2} \mathrm{O}_{3} \mathrm{ALD}$ coatings were prepared, and both their resistance to $\mathrm{AO}$ attack and their ability to reduce gas-surface energy transfer were characterized. Beams containing atomic and molecular oxygen, traveling at Earth-orbital velocities of $\sim 8 \mathrm{~km} \mathrm{~s}^{-1}$, were used to expose the test coupons to an AO fluence of $>1.2 \times 10^{21} \mathrm{O}$ atoms $\mathrm{cm}^{-2}$. The coated materials showed essentially no change, while the uncoated materials eroded slightly and their surfaces became rough. Representative samples of AO-exposed coated and uncoated material, as well as a polished sapphire surface for reference, were used for molecular beam-surface scattering experiments, in which the translational energy and angular distributions of inelastically scattered $\mathrm{O}$ and $\mathrm{O}_{2}$ were obtained, following impingement on the sample surfaces with a grazing incident angle of $\theta_{i}=70^{\circ}$ with respect to the surface normal. The beam surfacescattering experiments clearly demonstrate that $\mathrm{O}$ and $\mathrm{O}_{2}$ traveling at orbital velocities scatter directly from $\mathrm{Al}_{2} \mathrm{O}_{3}$ ALD-coated POSS-polyimide materials into the forward direction, leading to low momentum and energy transfer to the surface. Similar scattering dynamics were observed from the polished sapphire reference surface. Uncoated POSS-polyimide surfaces that had been roughened by prior AO exposure led to scattering with much more momentum and energy transfer than did the coated surfaces, as evidenced by broader angular distributions and lower final energies. The molecular beam-surface scattering data were used to parametrize a CLL scattering model, which was then used in DSMC simulations of drag on a representative satellite in VLEO. The simulations revealed that the use of the $\mathrm{Al}_{2} \mathrm{O}_{3}$ ALD-coated POSSpolyimides investigated here could reduce the drag to less than one half that of an identical satellite that uses materials which allow full energy accommodation of the incident atoms and molecules (i.e., the fully diffuse scattering limit). On the other hand, the use of uncoated AO-exposed POSS-polyimides was only predicted to lead to a modest reduction in drag of $10-20 \%$ compared to the diffuse scattering limit. The poor performance of the uncoated materials with respect to drag is the result of their surface roughness, which promotes energy transfer and scattering angle randomization, thus increasing momentum accommodation. Although the POSS-polyimide materials are highly AO-resistant, their surfaces become significantly roughened during atomic-oxygen exposure. Thus, a coating with an effectively smooth gas- 
surface interaction potential is key to promoting minimal accommodation and therefore minimal drag. An AO-resistant substrate is still desirable, because it will minimize the undercutting of the coating around a defect and prevent the defect from growing and significantly roughening the surface. The tested materials show remarkable promise as low-drag, AO-resistant materials for VLEO applications, but further optimization of the materials could improve their predicted performance. Because of the conformal nature of the ALD coating, the $\mathrm{Al}_{2} \mathrm{O}_{3}$ ALD-coated POSS-polyimide surfaces have roughnesses that are determined by the substrate roughnesses. It is anticipated that the coated surfaces could be made even smoother and more drag-reducing by optimizing the processing of the substrate films to minimize their roughnesses. The resulting drag reduction might not be trivial and could amount to an additional lowering of the drag by 10$20 \%$, relative to the diffuse scattering limit, over the tested materials. Besides improvements in the materials and their processing, more comprehensive experimental data could lead to a more accurate gassurface scattering model for the DSMC simulations. The current experiments only probed scattering in one plane, and the DSMC simulations only treated in-plane scattering. Futhermore, the current experiments focused on just one angle of incidence, requiring an extrapolation of the model to account for the many incident angles on surfaces of a satellite in VLEO. It would therefore be useful to collect a broader range of scattering dynamics data for both in-plane and out-of-plane scattering angles corresponding to a variety of incident angles, in order to generate a robust gas-surface model. With accurate modeling, grounded in high-fidelity molecular beam-surface scattering experiments, the relationship between measurable surface characteristics and drag could be explored, thus guiding the optimization of new materials for VLEO.

\section{Acknowledgments}

This work was supported by Skeyeon, Inc. 


\section{Conflicts of Interest / Competing Interests}

Two of the authors, T. K. Minton and T. E. Schwartzentruber, are members of the expert advisory board

for Skeyeon, Inc., who holds a U.S. patent on low-drag, AO-resistant materials based on the technology described in this article. C. Xu has no conflicting or competing interests. 


\section{References}

1. Llop, J. V., Roberts, P., Hao, Z., Tomas, L. R., and Beauplet, V.: Very low earth orbit mission concepts for earth observation: Benefits and challenges, Reinventing Space Conference, 18-21 (2014).

2. Kuiper, H. and Dolkens, D.: A cutting edge 6U CubeSat ADCS design for Earth observation with submeter spatial resolution at 230-380 km altitude, CEAS Space J. 12, 613-621 (2020).

3. Roberts, P. C., Crisp, N. H., Edmonson, S., García-Almiñana, D., García Berenguer, M., Rodríguez Donaire, S., and Sureda Anfres, M.: DISCOVERER: Developing Technologies to Enable Commercial Satellite Operations in Very Low Earth Orbit, Proceedings of the International Astronautical Congress, 1-5 (2020).

4. Sasaki, M.: Mission for Super-Low Earth Orbit, SLATS., Space Research Today 198, 10-18 (2017).

5. Champion, K., Cole, A., and Kantor, A.: Standard and reference atmospheres, Handbook of geophysics and the space environment Ch. 14, (1985).

6. Jursa, A. S.: US standard atmosphere, US Government Printing Office, Washington DC, (1976).

7. Roble, R. G.: Energetics of the mesosphere and thermosphere, the upper mesosphere and lower thermosphere: A review of experiment and theory, Geophys. Monogr. Ser 87, 1-21 (1995).

8. Visentine, J. T.: Environmental definition of the Earth's neutral atmosphere, NASA/SDIO Space Environmental Effects on Materials Workshop, , 179-195 (1989).

9. Banks, B. A., Rutledge, S. K., Auer, B. M., and DiFilippo, F.: Atomic oxygen undercutting of defects on $\mathrm{SiO}_{2}$ protected polyimide solar array blankets, Materials Degradation in Low Earth Orbit: Proc. of a Symposium sponsored by the ASM Joint Corrosion and Environmental Effects Committee 119th Ann. Meeting of the Minerals, Metals, and Materials, (1990).

10. Murad, E.: Spacecraft interaction with atmospheric species in low Earth orbit, J. Spacecr. Rockets 33, 131-136 (1996).

11. Banks, B. A., De Groh, K. K., Rutledge, S. K., and DiFilippo, F. J.: Prediction of in space durability of protected polymers based on ground laboratory thermal energy atomic oxygen, Protection of Materials and Structures from the Low Earth Orbit Space Environment 2, 89-100 (1999).

12. Gregory, J. C. and Peters, P. N.: The reactions of $5 \mathrm{eV}$ oxygen atoms with polymeric and carbon surfaces in orbit, atomic-oxygen effects measurements for Shuttle missions STS-8 and 41-G. In NASA TM 100459; Visentine, J., Ed 2, 4.1-4.5 (1988).

13. Teichman, L. A. and Stein, B. A.: NASA/SDIO Space Environmental Effects on Materials Workshop, NASA CP 3035, (1989).

14. Koontz, S. L., Albyn, K., and Leger, L. J.: Atomic oxygen testing with thermal atom systems: A critical evaluation, J. Spacecr. Rockets 28, 315-323 (1991).

15. Tennyson, R. C.: Atomic oxygen effects on polymer-based materials, Can. J. Phys. 69, 1190-1208 (1991).

16. Packirisamy, S., Schwam, D., and Litt, M.: Atomic oxygen resistant coatings for low Earth orbit space structures, J. Mater. Sci. 30, 308-320 (1995).

17. Minton, T. K. and Garton, D. J.: Dynamics of atomic-oxygen-induced polymer degradation in low earth orbit, Chemical Dynamics in Extreme Environments 11, 420-489 (2001).

18. Zhang, J. and Minton, T. K.: Production of volatile $\mathrm{CO}$ and $\mathrm{CO}_{2}$ from oxidized polyethylene and graphite surfaces by hyperthermal atom-surface collisions, High Perform. Polym. 13, S467-S482 (2001).

19. Zhang, J., Garton, D. J., and Minton, T. K.: Reactive and inelastic scattering dynamics of hyperthermal oxygen atoms on a saturated hydrocarbon surface, J. Chem. Phys. 117, 6239-6251 (2002).

20. Buczala, D. M., Brunsvold, A. L., and Minton, T. K.: Erosion of Kapton H by hyperthermal atomic oxygen, J. Spacecr. Rockets 43, 421-425 (2006). 
21. De Groh, K. K., Banks, B. A., Mccarthy, C. E., Rucker, R. N., Roberts, L. M., and Berger, L. A.: MISSE 2 PEACE polymers atomic oxygen erosion experiment on the international space station, High Perform. Polym. 20, 388-409 (2008).

22. Dever, J. A., Miller, S. K., Sechkar, E. A., and Wittberg, T. N.: Space environment exposure of polymer films on the materials international space station experiment: Results from MISSE 1 and MISSE 2, High Perform. Polym. 20, 371-387 (2008).

23. Verker, R., Grossman, E., and Eliaz, N.: Erosion of POSS-polyimide films under hypervelocity impact and atomic oxygen: The role of mechanical properties at elevated temperatures, Acta Mater. 57, 11121119 (2009).

24. Tagawa, M., Yokota, K., Kishida, K., Okamoto, A., and Minton, T. K.: Energy dependence of hyperthermal oxygen atom erosion of a fluorocarbon polymer: relevance to space environmental effects, ACS Appl. Mater. Interfaces 2, 1866-1871 (2010).

25. Tagawa, M. and Minton, T. K.: Mechanistic studies of atomic oxygen reactions with polymers and combined effects with vacuum ultraviolet light, MRS bulletin 35, 35-40 (2010).

26. Chambers, A. R.: Materials in Space: An Introduction and Overview, Encyclopedia of Aerospace Engineering, (2010).

27. Miller, S. K. and Banks, B.: Degradation of spacecraft materials in the space environment, MRS bulletin 35, 20-24 (2010).

28. Brunsvold, A. L., Minton, T. K., Gouzman, I., Grossman, E., and Gonzalez, R.: An investigation of the resistance of polyhedral oligomeric silsesquioxane polyimide to atomic-oxygen attack, High Perform. Polym. 16, 303-318 (2004).

29. Verker, R.: Effect of a Simulated Low Earth Orbit Environment on Durability of Poss-Polyimide Hybrid Nanocomposites, Ph.D. Thesis, Tel Aviv University, (2011).

30. Minton, T. K., Wright, M. E., Tomczak, S. J., Marquez, S. A., Shen, L. H., Brunsvold, A. L., Cooper, R., Zhang, J. M., Vij, V., Guenthner, A. J., and Petteys, B. J.: Atomic oxygen effects on POSS polyimides in low Earth orbit, ACS Appl. Mater. Interfaces 4, 492-502 (2012).

31. Qian, M., Murray, V. J., Wei, W., Marshall, B. C., and Minton, T. K.: Resistance of POSS polyimide blends to hyperthermal atomic oxygen attack, ACS Appl. Mater. Interfaces 8, 33982-33992 (2016).

32. Wright, J. S., Jones, A., Farmer, B., Rodman, D. L., and Minton, T. K.: POSS-enhanced colorless organic/inorganic nanocomposite (CORIN) for atomic oxygen resistance in low earth orbit, CEAS Space J., 1-15 (2021).

33. St. Clair, A. K., St. Clair, T.L.: Process for preparing highly optically transparent/colorless aromatic polyimide film., US Patent No. 4,603,061, (1986).

34. Banks, B. A., Snyder, A., Miller, S. K., de Groh, K. K., and Demko, R.: Atomic-oxygen undercutting of protected polymers in low Earth orbit, J. Spacecr. Rockets 41, 335-339 (2004).

35. Banks, B. A. d. G., K. K.; Miller, S. K. : Low Earth orbital atomic oxygen interactions with spacecraft materials, NASA Technical Memorandum 2004-213400, (2004).

36. Rettner, C. T., Barker, J. A., and Bethune, D. S.: Angular and velocity distributions characteristic of the transition between the thermal and structure regimes of gas-surface scattering, Phys. Rev. Lett. 67, 2183-2186 (1991).

37. Kleyn, A. W.: Molecular beams and chemical dynamics at surfaces, Chem. Soc. Rev. 32, 87-95 (2003).

38. Murray, V. J., Pilinski, M. D., Smoll Jr, E. J., Qian, M., Minton, T. K., Madzunkov, S. M., and Darrach, M. R.: Gas-surface scattering dynamics applied to concentration of gases for mass spectrometry in tenuous atmospheres, J. Phys. Chem. C 121, 7903-7922 (2017).

39. King, M. E., Nathanson, G. M., Hanninglee, M. A., and Minton, T. K.: Probing the microscopic corrugation of liquid surfaces with gas-liquid collisions, Phys. Rev. Lett. 70, 1026-1029 (1993). 
40. King, M. E., Fiehrer, K. M., Nathanson, G. M., and Minton, T. K.: Effects of thermal roughening on the angular distributions of trapping and scattering in gas-liquid collisions, J. Phys. Chem. A 101, 6556-6561 (1997).

41. Minton, T. K., Tagawa, M., and Nathanson, G. M.: Energy accommodation in hyperthermal gassurface collisions: Aerobraking in planetary atmospheres, J. Spacecr. Rockets 41, 389-396 (2004).

42. Wu, B., Zhang, J., Minton, T. K., McKendrick, K. G., Slattery, J. M., Yockel, S., and Schatz, G. C.: Scattering dynamics of hyperthermal oxygen atoms on ionic liquid surfaces:[emim] $\left[\mathrm{NTf}_{2}\right]$ and $\left[\mathrm{C}_{12} \mathrm{mim}\right]\left[\mathrm{NTf}_{2}\right]$, J. Phys. Chem. C 114, 4015-4027 (2010).

43. Alexander, W. A., Zhang, J., Murray, V. J., Nathanson, G. M., and Minton, T. K.: Kinematics and dynamics of atomic-beam scattering on liquid and self-assembled monolayer surfaces, Faraday Discuss. 157, 355-374 (2012).

44. Smoll, E. J. and Minton, T. K.: Scattering-angle randomization in nonthermal gas-liquid collisions, J. Phys. Chem. C 123, 22887-22896 (2019).

45. George, S. M.: Atomic layer deposition: an overview, Chem. Rev. 110, 111-131 (2010).

46. Cooper, R., Upadhyaya, H. P., Minton, T. K., Berman, M. R., Du, X., and George, S. M.: Protection of polymer from atomic-oxygen erosion using $\mathrm{Al}_{2} \mathrm{O}_{3}$ atomic layer deposition coatings, Thin Solid Films 516, 4036-4039 (2008).

47. Minton, T. K., Wu, B., Zhang, J., Lindholm, N. F., Abdulagatov, A. I., O’Patchen, J., George, S. M., and Groner, M. D.: Protecting polymers in space with atomic layer deposition coatings, ACS Appl. Mater. Interfaces 2, 2515-2520 (2010).

48. Koontz, S. L., Leger, L. J., Visentine, J. T., Hunton, D. E., Cross, J. B., and Hakes, C. L.: EOIM-III mass-spectrometry and polymer chemistry - STS-46, July-August 1992, J. Spacecr. Rockets 32, 483495 (1995).

49. Garton, D. J., Brunsvold, A. L., Minton, T. K., Troya, D., Maiti, B., and Schatz, G. C.: Experimental and theoretical investigations of the inelastic and reactive scattering dynamics of $\mathrm{O}\left({ }^{3} \mathrm{P}\right)+\mathrm{D}_{2} \mathrm{~J}$. Phys. Chem. A 110, 1327-1341 (2006).

50. Garton, D. J., Minton, T. K., Maiti, B., Troya, D., and Schatz, G. C.: A crossed molecular beams study of the $\mathrm{O}\left({ }^{3} \mathrm{P}\right)+\mathrm{H}_{2}$ reaction: Comparison of excitation function with accurate quantum reactive scattering calculations, J. Chem. Phys. 118, 1585-1588 (2003).

51. Troya, D., Schatz, G. C., Garton, D. J., Brunsvold, A. L., and Minton, T. K.: Crossed beams and theoretical studies of the $\mathrm{O}\left({ }^{3} \mathrm{P}\right)+\mathrm{CH}_{4} \rightarrow \mathrm{H}+\mathrm{OCH}_{3}$ reaction excitation function, J. Chem. Phys. 120, 731-739 (2004).

52. Novastrat ${ }^{\circledR} 905$ : http://nexolvematerials.com/low-and-zero-cte-polyimides/novastrat-905

53. Dillon, A. C., Ott, A. W., Way, J. D., and George, S. M.: Surface-chemistry of $\mathrm{Al}_{2} \mathrm{O}_{3}$ deposition using $\mathrm{Al}\left(\mathrm{CH}_{3}\right)_{3}$ and $\mathrm{H}_{2} \mathrm{O}$ in a binary reaction sequence, Surf. Sci. 322, 230-242 (1995).

54. Ott, A. W., Klaus, J. W., Johnson, J. M., and George, S. M.: $\mathrm{Al}_{3} \mathrm{O}_{3}$ thin film growth on $\mathrm{Si}(100)$ using binary reaction sequence chemistry, Thin Solid Films 292, 135-144 (1997).

55. Brunsvold, A. L., Zhang, J., Upadhyaya, H. P., and Minton, T. K.: Beam-surface scattering studies of the individual and combined effects of VUV radiation and hyperthermal $\mathrm{O}, \mathrm{O}_{2}$, or Ar on FEP Teflon surfaces, ACS Appl. Mater. Interfaces 1, 187-196 (2009).

56. Murray, V. J., Marshall, B. C., Woodburn, P. J., and Minton, T. K.: Inelastic and reactive scattering dynamics of hyperthermal $\mathrm{O}$ and $\mathrm{O}_{2}$ on hot vitreous carbon surfaces, J. Phys. Chem. C 119, 1478014796 (2015).

57. Marshall, B. C., Smoll Jr, E. J., Purcell, S. M., Costen, M. L., McKendrick, K. G., and Minton, T. K.: Scattering dynamics of oxygen atoms on imidazolium tetrafluoroborate ionic liquid surfaces: Dependence on alkyl chain length, J. Phys. Chem. C 120, 12472-12483 (2016).

58. Xu, C. and Minton, T. K.: Effect of N atoms on O-Atom Reactivity with Carbon, J. Spacecr. Rockets, 1-4 (2021). 
59. Murray, V. J., Smoll Jr, E. J., and Minton, T. K.: Dynamics of graphite oxidation at high temperature, J. Phys. Chem. C 122, 6602-6617 (2018).

60. Bird, G. A.: Molecular Gas Dynamics and the Direct Simulation of Gas Flows, Oxford University Press, (1994).

61. Poovathingal, S. J., Xu, C., Murray, V. J., Minton, T. K., and Schwartzentruber, T. E.: Gas-surface model in DSMC for molecules passing through a funnel-type gas concentrator, in Proceedings of the 2019 AIAA Scitech Forum,San Diego, CA, January 7-11, 2019. Paper No. AIAA-2019-1281, (2019).

62. Boyd, I. D. and Schwartzentruber, T. E.: Nonequilibrium Gas Dynamics and Molecular Simulation, Cambridge University Press, (2017).

63. Lord, R. G.: Application of the Cercignani-Lampis scattering kernel to direct simulation Monte Carlo calculations, Proceedings of the 17th International Symposium on Rarefied Gas Dynamics, VCH, Weinheim, Germany, 1427-1433 (1991).

64. Padilla, J. F. and Boyd, I. D.: Assessment of gas-surface interaction models for computation of rarefied hypersonic flow, J. Thermophys. Heat Tr. 23, 96-105 (2009). 